Article

\title{
Synthesis of Nano-Zinc Oxide Loaded on Mesoporous Silica by Coordination Effect and Its Photocatalytic Degradation Property of Methyl Orange
}

\author{
Zhichuan Shen ${ }^{1,2}$, Hongjun Zhou ${ }^{1,2, *}$, Huayao Chen ${ }^{1,2}$, Hua Xu ${ }^{1,2}$, Chunhua Feng ${ }^{3}$ \\ and Xinhua Zhou 1,2,* \\ 1 School of Chemistry and Chemical Engineering, Zhongkai University of Agriculture and Engineering, \\ Guangzhou 510220, China; szcraiser@163.com (Z.S.); huayao_011@163.com (H.C.); \\ dlutxuhua@163.com (H.X.) \\ 2 Guangzhou Key Lab for Efficient Use of Agricultural Chemicals, Guangzhou 510220, China \\ 3 School of Environment and Energy, South China University of Technology, Guangzhou 510220, China; \\ chfeng@scut.edu.cn \\ * Correspondence: hongjunzhou@163.com (H.Z.); cexinhuazhou@163.com (X.Z.); \\ Tel.: +86-020-8900-3114 (H.Z. \& X.Z.); Fax: +86-020-8900-3114 (H.Z. \& X.Z.)
}

Received: 28 March 2018; Accepted: 7 May 2018; Published: 9 May 2018

\begin{abstract}
Salicylaldimine-modified mesoporous silica (Sal-MCM-3 and Sal-MCM-9) was prepared through a co-condensation method with different amounts of added salicylaldimine. With the coordination from the salicylaldimine, zinc ions were impregnated on Sal-MCM-3 and Sal-MCM-9. Then, Zn-Sal-MCM-3 and Zn-Sal-MCM-9 were calcined to obtain nano-zinc oxide loaded on mesoporous silica (ZnO-MCM-3 and $\mathrm{ZnO}-\mathrm{MCM}-9$ ). The material structures were systematically studied by Fourier transform infrared spectroscopy (FTIR), $\mathrm{N}_{2}$ adsorption/desorption measurements, $\mathrm{X}$-ray powder diffraction (XRD), zeta potential, scanning electron microscopy (SEM), transmission electron microscopy (TEM), X-ray photoelectron spectroscopy (XPS), ultraviolet diffused reflectance spectrum (UV-vis DRS), and thermogravimetry (TGA). Methyl orange (MO) was used to investigate the photocatalysis behavior of $\mathrm{ZnO}-\mathrm{MCM}-3$ and $\mathrm{ZnO}-\mathrm{MCM}-9$. The results confirmed that nano $\mathrm{ZnO}$ was loaded in the channels as well as the outside surface of mesoporous silica (MCM-41). The modification of salicylaldimine helped MCM-41 to load more nano ZnO on MCM-41. When the modification amount of salicylaldimine was one-ninth and one-third of the mass of the silicon source, respectively, the load of nano $\mathrm{ZnO}$ on $\mathrm{ZnO}-\mathrm{MCM}-9$ and $\mathrm{ZnO}-\mathrm{MCM}-3$ had atomic concentrations of 1.27 and 2.03, respectively. $\mathrm{ZnO}$ loaded on $\mathrm{ZnO}-\mathrm{MCM}-9$ had a wurtzite structure, while $\mathrm{ZnO}$ loaded on $\mathrm{ZnO}-\mathrm{MCM}-3$ was not in the same crystalline group. The blocking effect caused by nano $\mathrm{ZnO}$ in the channels reduced the orderliness of MCM-41. The photodegradation of MO can be divided in two processes, which are mainly controlled by the surface areas of $\mathrm{ZnO}-\mathrm{MCM}$ and the loading amount of nano $\mathrm{ZnO}$, respectively. The pseudo-first-order model was more suitable for the photodegradation process.
\end{abstract}

Keywords: nano $\mathrm{ZnO}$; mesoporous silica; salicylaldimine; coordination; photodegradation

\section{Introduction}

Nano zinc oxide (nano $\mathrm{ZnO}$ ), which is well known for its highly activity and abundance for numerous organocatalysis [1,2], has previously demonstrated its performance in many applications such as the antibacterial field and catalytic degradation field [3,4]. Especially in the field of photodegradation, nano $\mathrm{ZnO}$ has attracted extensive attention owing to its strong quantum confinement effects [5]. This nano semiconductor possesses a wide band gap energy as well as 
a large exciton binding energy of about $60 \mathrm{meV}$, which allows excitonic emissions even at room temperature [6-9]. Thus, it can harvest ultraviolet radiation and generate electron-hole pairs, which will react with oxygen, further leading to the formation of hydroxyl radicals, superoxide radical anions, and hydroperoxyl radicals [10]. However, unsupported nano $\mathrm{ZnO}$ has one major drawback as it usually aggregates during the photocatalytic process, which reduces its surface area and thereby reduces the generation of reactive oxygen for the degradation of reagents [11-13]. In order to enhance its dispersion, loading the nano $\mathrm{ZnO}$ on a high surface support such as mesoporous silica can solve this problem [14].

In the past decade, mesoporous silica had been considerably made as a structural basis for nanotechnological applications as it is porous, thermally stable, non-toxic and hydrothermally stable [15-19]. Furthermore, as it has uniform and tunable channels with a pore diameter ranging from $2 \sim 50 \mathrm{~nm}$, it can also be used to control the size of nanoparticles and make them homodisperse during their formation [6]. A good dispersion can help nanoparticles such as $\mathrm{ZnO}$ and $\mathrm{TiO}_{2}$ reduce the light scattering so that they demonstrate better photocatalytic properties $[20,21]$. These semiconductor nanoparticles can be incorporated inside the mesoporous silica by using various synthesis methods [22]. Among them, the impregnation method is most commonly used to load nano $\mathrm{ZnO}$ on mesoporous silica, which can help the nano $\mathrm{ZnO}$ form better crystallinity and provide a more direct path for the transfer of electrons, thus increasing photodegradation efficiency $[23,24]$. However, the limited loading amount of pure mesoporous silica is due to the lack of suitable active adsorption sites, which is still a problem during impregnation [25]. To solve this problem, chemical modification should be introduced to the mesoporous silica.

The surface of mesoporous silica is full of silanol groups which makes it easy to graft by chemical groups. Functional group anchoring can be achieved by using a functionalized silane or a co-condensation of silane with the silica or a post grafting of silica [26]. The introduction of organic compounds offers mesoporous silica specific adsorption sites for combination with metal ions. Chouyyok [27] reported that the chelating diamines modification made the mesoporous silica enhance the copper ions adsorption capacity in the waste water application due to the $\pi$ back-bonding between copper ions and Phen aromatic ring system. He [28] found that the GLYMO-IDA grafted mesoporous silica had a good capacity in the adsorption of nickel ions through its strong binding ability. Such functional modifications can build the chemical bond between mesoporous silica and metal ions with a vacant electron orbit to improve the loading amount of metal ions. Nevertheless, fewer studies have paid much attention to this method in the application of loading metal oxide onto mesoporous silica. Only two studies have reported that nano $\mathrm{ZnO}$ were loaded inside the mesoporous silica by functionalizing the surface of MCM-41 using ethylene diamine [29,30]. In this system, the loading amount of $\mathrm{ZnO}$ was more than that of using pure MCM-41. Hence, the method of using functionalized mesoporous silica to make more nano $\mathrm{ZnO}$ loaded on mesoporous silica requires more research.

In this work, salicylaldimine, a kind of Schiff base, was used to adsorb zinc ions as a precursor for $\mathrm{ZnO}$ because of their straightforward synthesis and stability as well as their strong coordination with metal ions. On the one hand, owing to the $\pi$-system consisting of a benzene ring, phenolic hydroxyl, and carbon-nitrogen double bond, the salicylaldimine can play a key role as a chelating ring [31]. On the other hand, because empty orbitals exist, zinc ions can be regarded as the electron acceptor. These two factors together form the coordination bond between the zinc ion and salicylaldimine. Vasile [32] used a similar Schiff base modified mesoporous silica to adsorb copper ions where the adsorption capacity was $0.92 \mathrm{mmol} / \mathrm{g}$. Its molar ratio of $\mathrm{Cu} / \mathrm{N}$ was 0.42 , which was very close to the theoretical value of 0.5 . Salicylaldimine can be synthesized through the reaction of 3-Aminopropyltriethoxysilane with salicylaldehyde [33,34]. Then, by using the synthetic method of co-condensation or post-synthesis, the ethyoxyl of salicylaldimine will react with surface silanol groups of mesoporous silica [35], so that a certain amount of salicylaldimine is grafted onto the mesoporous silica. According to our knowledge, using a Schiff base modified mesoporous silica to adsorb zinc ions as a precursor of nano $\mathrm{ZnO}$ has not yet been reported and this method is worth exploring. 
Herein, nano $\mathrm{ZnO}$ was loaded onto the surface of MCM-41 by oxidizing the zinc ions caught by the salicylaldimine modified MCM-41. A series of characterization tests were undertaken to analyze the structure of the materials. The properties and the kinetic behavior of the system were also evaluated by photodegradating the methyl orange, a commonly used coloring agent pollutant [36].

\section{Experimental}

\subsection{Chemicals}

Cetyl trimethyl ammonium bromide (CTAB), tetraethyl orthosilicate (TEOS), 3-Aminopropyltriethyloxy silane (APTES), and salicylaldehyde were all obtained from Shanghai Aladdin Biochemical Reagents (Shanghai, China). Ethanol, dichloromethane, anhydrous magnesium sulfate, ammonia solution (wt $=25 \%$ ), zinc nitrate, and methyl orange (MO) were obtained from Tianjin Damao Chemical Reagents (Tianjin, China). All chemicals were analytical grade and used as received without any further purification.

\subsection{Synthesis}

\subsubsection{Preparation of Salicylaldimine}

According to the literature [34], $8.85 \mathrm{~g}$ (39.98 $\mathrm{mmoL})$ of APTES, $4.88 \mathrm{~g}$ (39.96 $\mathrm{mmoL})$ of salicylaldehyde, and $100 \mathrm{~mL}$ of ethanol were added to a flask and reacted at $95{ }^{\circ} \mathrm{C}$ for $3 \mathrm{~h}$. After removing ethanol with rotary evaporation, the intermediate products were dissolved in $10 \mathrm{~mL}$ (156.01 $\mathrm{mmoL}$ ) of dichloromethane. Then, the product was washed with deionized water three times. After being left to stand for $12 \mathrm{~h}$, the organic layer was extracted, and $0.5 \mathrm{~g}(4.15 \mathrm{mmoL})$ anhydrous magnesium sulfate was used to remove the residual water. Finally, the final product was filtered to remove dichloromethane and magnesium sulfate to obtain salicylaldimine. According to FTIR (Figure 1), Peaks appearing at $780 \mathrm{~cm}^{-1}$ and $1630 \mathrm{~cm}^{-1}$ of Sal were attributed to the the vibration band of the benzene ring and the stretching band of $\mathrm{C}=\mathrm{N}$, which mean that the successful synthesis of salicylaldimine.

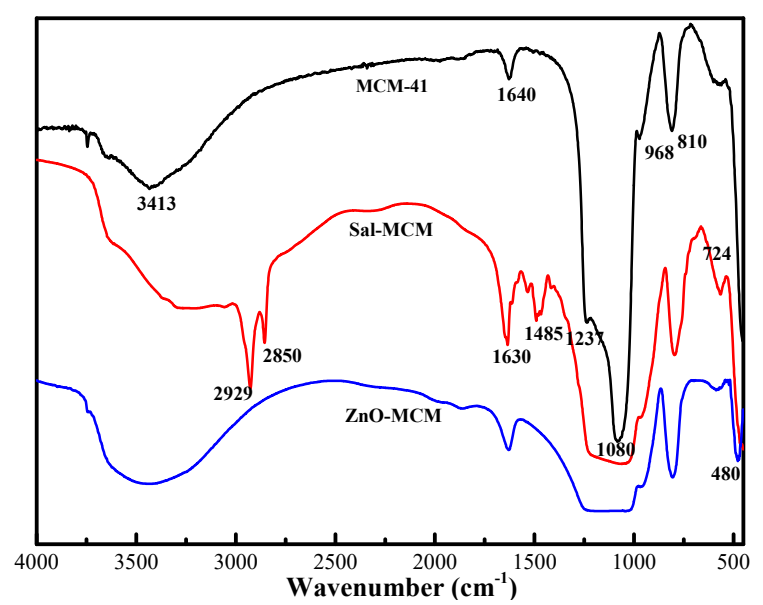

Figure 1. Fourier-transform infrared spectroscopy (FTIR) spectra of MCM-41, Sal, Sal-MCM, and $\mathrm{ZnO}-\mathrm{MCM}$.

\subsubsection{Preparation of Salicylaldimine-Modified Mesoporous Silica (Sal-MCM)}

As reported previously [37], the co-condensation synthesis method was used to prepare Sal-MCM. In a typical process, a total of $1.5 \mathrm{~g}(4.12 \mathrm{mmoL})$ of CTAB, $105 \mathrm{~mL}$ of ammonia solution $(\mathrm{wt}=25 \%)$, and $150 \mathrm{~mL}$ of deionized water were added to the flask to be completely dissolved at $60{ }^{\circ} \mathrm{C}$ with $1 \mathrm{~h}$ of stirring. Then, $7.5 \mathrm{~g}$ (35.28 mmoL) of TEOS was added to the solution dropwise. After $1 \mathrm{~h}$, $2.5 \mathrm{~g}$ of the as-synthesized salicylaldimine was added, and the reaction was stirred for another $6 \mathrm{~h}$ 
before being crystallized for $24 \mathrm{~h}$ at $30^{\circ} \mathrm{C}$, filtered, washed, and dried at $80^{\circ} \mathrm{C}$. At last, the template was removed with $100 \mathrm{~mL}$ ethanol at $110{ }^{\circ} \mathrm{C}$ for $72 \mathrm{~h}$ by the mean of reflux extraction to obtain Sal-MCM-41. Two kinds of samples were prepared and denoted as Sal-MCM-3 and Sal-MCM-9, which represented the modification amount of salicylaldimine as one-third and one-ninth of the mass of TEOS, respectively. Additionally, mesoporous silica without salicylaldimine modification was synthesized and noted as MCM-41.

\subsubsection{Preparation of Zinc Oxide Supported by Mesoporous Silica (ZnO-MCM)}

Zinc oxide nanoparticles were loaded onto mesoporous silica through a wet impregnation method (Scheme $1 \mathrm{~A}$ total of $50 \mathrm{~mL}$ (100 mmoL) of zinc nitrate solution was added to $500 \mathrm{mg}$ of Sal-MCM-41 or MCM-41 at $30{ }^{\circ} \mathrm{C}$ with stirring for $24 \mathrm{~h}$. Then, $\mathrm{Zn} / \mathrm{Sal}-\mathrm{MCM}-41$ and $\mathrm{Zn} / \mathrm{MCM}-41$ was obtained after being filtered, washed, and dried. Finally, following calcination at $550^{\circ} \mathrm{C}$ for $6 \mathrm{~h}$ in air, $\mathrm{ZnO}-\mathrm{MCM}$ was obtained. The samples were noted as ZnO-MCM-3, ZnO-MCM-9, and ZnO-MCM-0, where 3, 9, and 0 represent that the samples were prepared by Sal-MCM-3, Sal-MCM-9, and MCM-41, respectively.

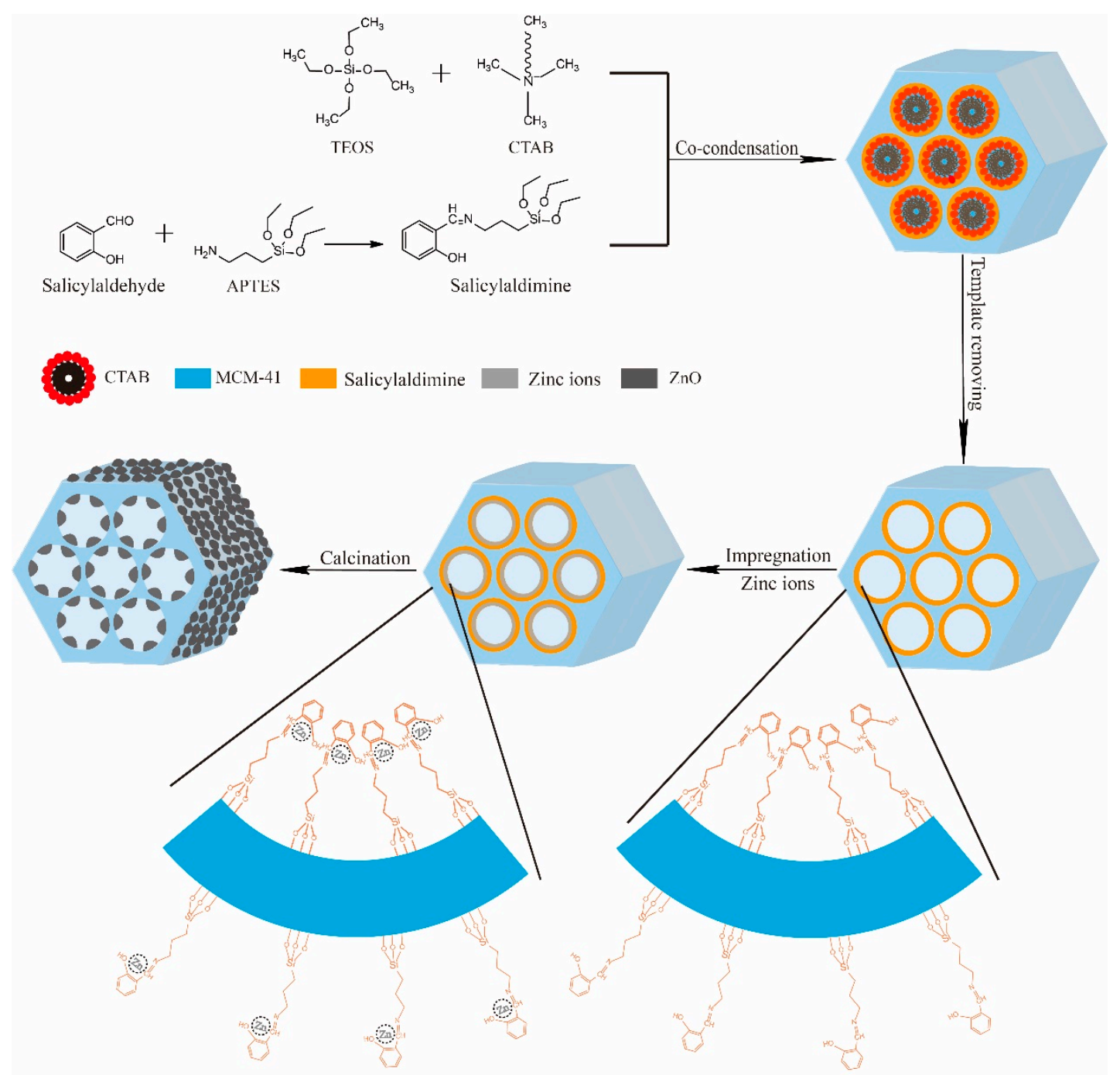

Scheme 1. Schematic illustration of the synthetic process of ZnO-MCM.

\subsection{Photocatalytic Degradation of MO and Reusablity Study}

The photoefficiency of ZnO-MCM was evaluated through the degradation of an MO aqueous solution under UV-light irradiation. In a typical experiment, $50 \mathrm{mg}$ of $\mathrm{ZnO}-\mathrm{MCM}$ was dispersed in 
$100 \mathrm{~mL}$ of a $10 \mathrm{mg} / \mathrm{L}(0.003 \mathrm{mmoL}) \mathrm{MO}$ solution. Then, the suspension was exposed to a UV lamp (300 W, $365 \mathrm{~nm}$ wavelength) with stirring. To quantify the progress of the photodegradation reaction, $3 \mathrm{~mL}$ of sampling was taken out at $15 \mathrm{~min}$ intervals using a $1 \mathrm{~mL}$ pipette and centrifuged at $12,000 \mathrm{r} / \mathrm{min}$; then, a $0.2 \mu \mathrm{m}$ Millipore membrane filter was used to completely remove the residual $\mathrm{ZnO}-\mathrm{MCM}$ nanoparticles to avoid its interference on subsequent MO absorbance analysis. A UV Lambda 365 ultraviolet-visible spectrometer from Perkin Elmer (Waltham, MA, USA) was applied to measure the amount of $\mathrm{MO}$ degraded by $\mathrm{ZnO}-\mathrm{MCM}$. A linear regression for the relationship between the solution concentration $(C)$ and absorbance $(A)$ of the $\mathrm{MO}$ standard solutions at different concentrations was performed at $\lambda=463 \mathrm{~nm}$ to obtain a standard curvilinear equation: $A=0.06746 C+0.04755$; $R^{2}=0.99906$. The efficiency of the photocatalytic activity was calculated using the following equation:

$$
D A=\frac{\left(C_{0}-C_{t}\right)}{C_{0}} \times 100 \%
$$

where $C_{0}$ is the original mass concentration $(\mathrm{mg} / \mathrm{L})$ of the $\mathrm{MO}$ aqueous solution, and $C_{t}$ is the mass concentration $(\mathrm{mg} / \mathrm{L})$ of the $\mathrm{MO}$ aqueous solution at the relevant time interval. For contrast, the photocatalytic property of $\mathrm{ZnO}-\mathrm{MCM}-0$ and the self-degradation of $\mathrm{MO}$ were also examined.

The reusability of a selected ZnO-MCM sample was examined. For this purpose, the photocatalyst was filtered off after reaction, washed several times using distilled water, centrifuged (5000 r/min for $15 \mathrm{~min}$ ), and subsequently dried at $80{ }^{\circ} \mathrm{C}$ in an oven. Then, it was reused as such for subsequent experiments (up to six cycles) under similar reaction conditions. For each cycle, the photocatalyst was reused for the photodegradation of a fresh $\mathrm{MO}$ solution. The same initial concentration of $\mathrm{MO}$ was used for each cycle $(100 \mathrm{~mL}, 10 \mathrm{mg} / \mathrm{L})$ and an irradiation time of $120 \mathrm{~min}$ was used.

\subsection{Characterization}

The samples were analyzed using a Bruker AXS D8 X-ray diffractometer (Bruker AXS GmbH, Karlsruhe, Germany) with $\mathrm{Cu} \mathrm{K} \alpha$ radiation $\left(\lambda=1.5418 \AA\right.$ ) and a graphite monochromator at $25^{\circ} \mathrm{C}$, $40 \mathrm{kV}$, and $30 \mathrm{~mA}$. The measurements were scanned at $2^{\circ} / \mathrm{min}$ (angular range $2 \theta=0.5-5^{\circ}$ and $5-90^{\circ}$ ) in a $0.02^{\circ}$ step size. The morphology of the particles was analyzed by a Spectrum 100 Fourier infrared spectrometer (Perkin-Elmer, Waltham, MA, USA) using the KBr squash technique. Gold particles were sprayed onto the surface of the samples under the protection of $\mathrm{N}_{2}$, and the samples were characterized by a $\$ 4800$ scanning electron microscope (Hitachi, Tokyo, Japan) to observe the surface topography. Transmission electron microscopy (TEM) observation was conducted on an FEI Tecnai G2 F20 transmission (Thermo Fisher Scientific, Waltham, MA, USA) election microscope. The Brunauer-Emmett-Teller (BET) surface area of the samples was determined by $\mathrm{N}_{2}$ adsorption isotherms at $77 \mathrm{~K}$, operated on Quadrasorb SI adsorption equipment. The samples were degassed at $200{ }^{\circ} \mathrm{C}$ for $12 \mathrm{~h}$ in vacuum before the $\mathrm{N}_{2}$ adsorption experiment. The zeta potential and particle size of the samples were investigated with a Zetasizer Nano ZS (Bruker Corporation, Karlsruhe, Germany) in water at $\mathrm{pH}=7$ through ultrasonic dispersion. X-ray photo electron spectroscopy (XPS) were recorded on an ESCALAB 250Xi spectrometer (Thermo Fisher Scientific, Waltham, MA, USA, $\mathrm{Al} \mathrm{K} \alpha, h v=1486.6 \mathrm{eV}$ ) under a vacuum of $2 \times 10^{-7} \mathrm{~Pa}$. Charging effects were corrected by adjusting the main C 1 s peak to a position of $284.8 \mathrm{eV}$. A TGA 2 thermogravimetric analyzer (Mettler-Toledo, Columbus, $\mathrm{OH}, \mathrm{USA}$ ) was used to analyze the heat stability of the particles over the heating range of $40 \sim 800^{\circ} \mathrm{C}$ and heating rate of $10^{\circ} \mathrm{C} / \mathrm{min}$. The diffuse reflectance UV absorbance spectra of samples were recorded at $25^{\circ} \mathrm{C}$ using a UV-3600 spectrophotometer (Shimadzu, Kyoto, Japan), all samples were measured with $\mathrm{BaSO}_{4}$ as the reference. 


\section{Results and Discussion}

\subsection{Characterization}

In Figure 1, Fourier-transform infrared spectroscopy (FTIR) was adopted to compare the different compositions of MCM-41, Sal-MCM, and ZnO-MCM. For MCM-41, the bands located at $3413 \mathrm{~cm}^{-1}$ and $968 \mathrm{~cm}^{-1}$ were the stretching and bending vibrations of $\mathrm{Si}-\mathrm{OH}$, respectively [38]. The two bands that appeared at $1080 \mathrm{~cm}^{-1}$ and $810 \mathrm{~cm}^{-1}$ belonged to the characteristic peaks of $\mathrm{Si}-\mathrm{O}-\mathrm{Si}$ on the $\mathrm{SiO}_{2}$ framework. In comparison with MCM-41, two new bands appearing at $2929 \mathrm{~cm}^{-1}$ and $2850 \mathrm{~cm}^{-1}$ of Sal-MCM were attributed to the symmetric and non-symmetric C-H stretching vibration bands from the aminopropyl group. The vibration band of the benzene ring and the stretching band of $\mathrm{C}=\mathrm{N}$ in salicylaldimine were located at $780 \mathrm{~cm}^{-1}$ and $1630 \mathrm{~cm}^{-1}$, respectively. It proved that the mesoporous silica was well modified by salicylaldimine. Compared with MCM-41, a red shift at $480 \mathrm{~cm}^{-1}$ of $\mathrm{ZnO}-\mathrm{MCM}$ was observed, which indicated that $\mathrm{ZnO}$ was well incorporated in the channels of MCM-41 [39].

As shown in Figure 2a, the $\mathrm{N}_{2}$ adsorption/desorption isotherms of MCM-41, Sal-MCM-9, and Sal-MCM-3 belonged to the Langmuir IV type adsorption. Hysteresis loops in these isotherms were not obvious, which meant that the samples possessed a small pore size [40], while the pore size distribution analyzed by the NLDFT method also confirmed the occurrence of micropores, as shown in Figure $2 \mathrm{~b}$. The adsorption and desorption branches of Sal-MCM could not be easily duplicated within $p / p_{\mathrm{o}}=0.0$ to $p / p_{\mathrm{o}}=0.2$ due to a certain extent of chemical adsorption by salicylaldimine during the testing process [41]. In addition, as shown in Table 1, the modification of salicylaldimine would significantly decrease the BET surface, pore diameter, and pore volume due to the blocking effect of salicylaldimine. Moreover, the BET surface of Sal-MCM-3 and Sal-MCM-9 were $453.385 \mathrm{~m}^{2} / \mathrm{g}$ and $634.437 \mathrm{~m}^{2} / \mathrm{g}$, respectively, which meant that the salicylaldimine modification on Sal-MCM-3 was more than that of Sal-MCM-9. The modification of salicylaldimine not only decreased the pore size of the mesoporous silica, but also broadened the distribution.
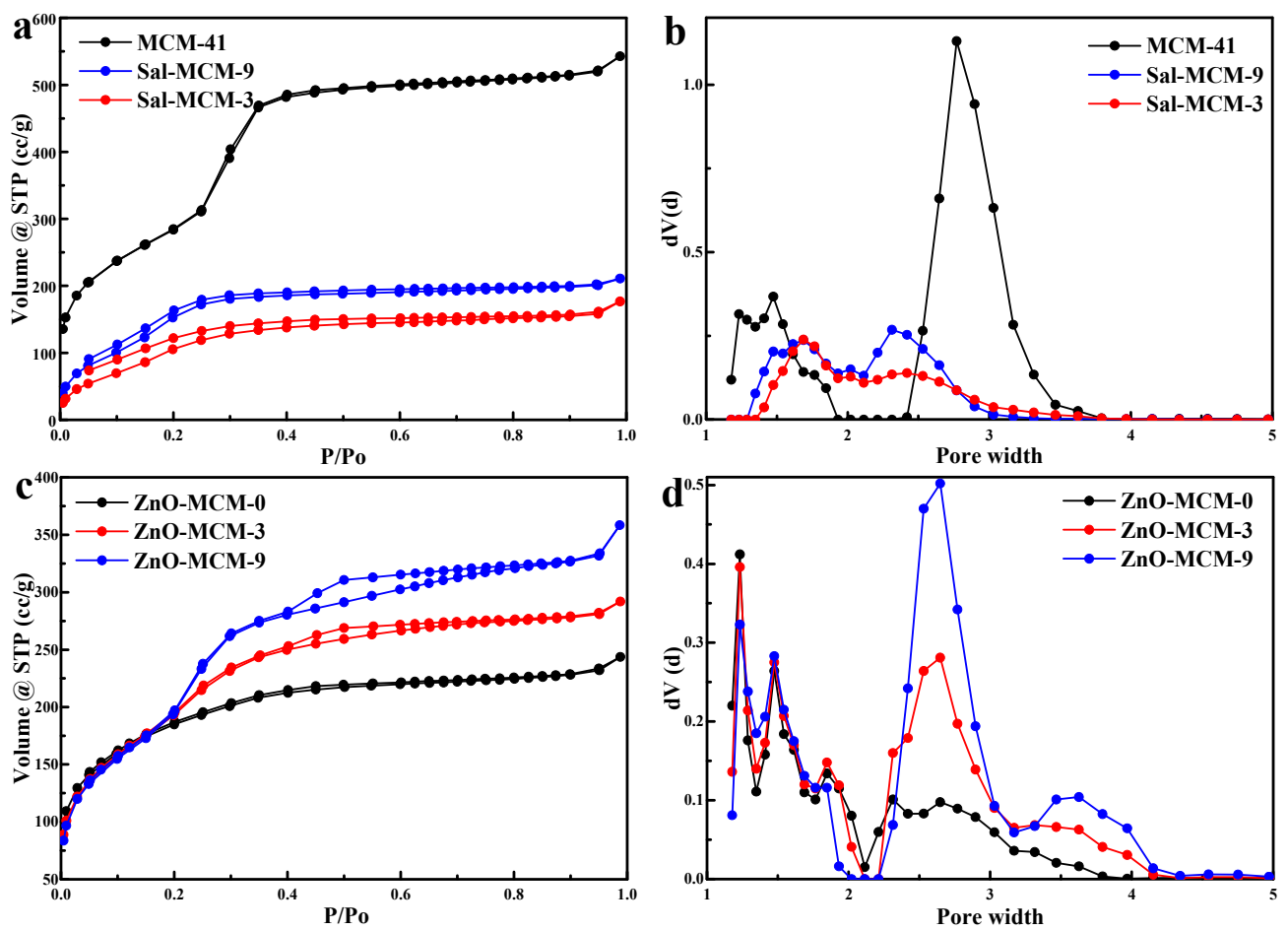

Figure 2. $\mathrm{N}_{2}$ adsorption/ desorption isotherms (a,b) and pore size distribution (c,d) of MCM-41, Sal-MCM, and ZnO-MCM. 
Table 1. The pore structural parameters of MCM-41, Sal-MCM, and ZnO-MCM.

\begin{tabular}{cccc}
\hline Materials & Surface Area $\left(\mathbf{m}^{2} / \mathbf{g}\right)$ & Pore Diameter Dv $(\mathbf{n m})$ & Pore Volume $\left(\mathbf{m}^{\mathbf{3}} / \mathbf{g}\right)$ \\
\hline MCM & 1187.377 & 2.444 & 0.993 \\
ZnO-MCM-0 & 625.657 & 0.887 & 0.429 \\
Sal-MCM-3 & 453.385 & 1.934 & 0.388 \\
ZnO-MCM-3 & 739.543 & 2.180 & 0.547 \\
Sal-MCM-9 & 634.437 & 1.932 & 0.478 \\
ZnO-MCM-9 & 848.967 & 2.176 & 0.682 \\
\hline
\end{tabular}

As shown in Figure 2c, after the load of $\mathrm{ZnO}$, the $\mathrm{N}_{2}$ adsorption/desorption isotherms of $\mathrm{ZnO}-\mathrm{MCM}-0, \mathrm{ZnO}-\mathrm{MCM}-3$ and $\mathrm{ZnO}-\mathrm{MCM}-9$ were still maintained as Langmuir IV types. Type $\mathrm{H} 4$ hysteresis loops were observed in the isotherms of ZnO-MCM-3 and ZnO-MCM-9 at $p / p_{\mathrm{o}}=0.4$, while the isotherm of $\mathrm{ZnO}-\mathrm{MCM}-0$ did not show any type of hysteresis loops. The appearance of the $\mathrm{H} 4$ hysteresis loop implied the instability of the adsorbed $\mathrm{N}_{2}$ due to the presence of $\mathrm{ZnO}$ in the pores of the mesoporous silica [40]. All the samples in Figure $2 \mathrm{~d}$ showed three kinds of microporous distributions. Particularly, two mesopore systems, one with a relatively narrower and smaller pore size and another with a larger and broader pore size, were observed for ZnO-MCM-3 and ZnO-MCM-9. In contrast, ZnO-MCM-0 only exhibited a wider and smaller mesoporous distribution. It was supported that the introduction of $\mathrm{ZnO}$ would make the mesoporous silica form a hierarchical characteristic structure. As shown in Table 1, due to the blocking effect of $\mathrm{ZnO}$, the BET surface, pore diameter, and pore volume decreased. Furthermore, when compared to MCM-41, the BET surface of ZnO-MCM-0, ZnO-MCM-3, and ZnO-MCM-9 decreased by about $561.72 \mathrm{~m}^{2} / \mathrm{g}, 447.834 \mathrm{~m}^{2} / \mathrm{g}$, and $338.410 \mathrm{~m}^{2} / \mathrm{g}$, respectively. It can be seen that the more salicylaldimine modifications the MCM-41 underwent, the more zinc ions would be adsorbed so that more nano $\mathrm{ZnO}$ would be supported on MCM-41. Additionally, it was obvious that both the changes of the BET surface of ZnO-MCM-3 and ZnO-MCM-9 were less than that of ZnO-MCM-0. This phenomenon proved that using the chemical groups modified on mesoporous silica to adsorb zinc ions would cause less damage to the surface areas of the vehicle than that of the simple physical adsorption of pure mesoporous silica before oxidizing zinc ions to $\mathrm{ZnO}$.

Figure 3 shows the low angle X-ray diffraction (LXRD) patterns of MCM-41, Sal-MCM-3, Sal-MCM-9, ZnO-MCM-3, and ZnO-MCM-9. Three characteristic peaks are shown in MCM-41, which could be ascribed to the (100), (110), and (200) crystal faces, indicating that the particles had a regular hexagonal pore structure [42]. The modification of salicylaldimine made the intensity of the low-angle XRD peaks decrease, especially in the (110) and (200) crystal face. Furthermore, when the amount of salicylaldimine increased, all of the crystal faces disappeared. All these phenomena identified that salicylaldimine was introduced to the system and decreased its degree of orderliness [43]. After the load of $\mathrm{ZnO}$, peaks of the (100) crystal face of both ZnO-MCM-3 and ZnO-MCM-9 shifted to a higher 20, which meant the occurrence of $\mathrm{ZnO}$ in the channels. In comparison to Sal-MCM-9, the intensity of the (100) crystal face peak of ZnO-MCM-9 decreased, and the peaks of the (110) and (200) crystal faces faded away. However, the pattern of ZnO-MCM-3 still maintained the same shape as that of Sal-MCM-3. This result proved that the degree of orderliness of salicylaldimine-modified MCM-41 is crucial for $\mathrm{ZnO}$ formation inside the channels, and it further affects the orderliness of $\mathrm{ZnO}-\mathrm{MCM}$.

Figure 3 also shows the wide-angle X-ray diffraction patterns (WXRD) of MCM-41, ZnO-MCM-0, $\mathrm{ZnO}-\mathrm{MCM}-3$, and ZnO-MCM-9. Compared with MCM-41, no characteristic peaks of ZnO were observed in these wide-angle patterns of $\mathrm{ZnO}-\mathrm{MCM}-0$ and $\mathrm{ZnO}-\mathrm{MCM}-3$. Only diffuse peaks of the non-crystalline silica appeared, meaning that $\mathrm{ZnO}$ was finely loaded on the mesoporous silica and the cluster size of $\mathrm{ZnO}$ was too small to be detected by $\mathrm{X}$-ray [44]. However, it also confirmed that $\mathrm{ZnO}$ was not present in the crystalline form [45], and the growth of $\mathrm{ZnO}$ was limited by the mesostructure of the vehicle. For ZnO-MCM-9, although the LXRD showed that the material was not in a good degree of orderliness, a series of peaks were still observed at the (100), (002), (101), and (110) crystal 
faces, which could be indexed to the wurtzite structure of $\mathrm{ZnO}$ [46]. Combined with the blocking effect confirmed by the $\mathrm{N}_{2}$ adsorption/desorption, it meant that the bad degree of orderliness of ZnO-MCM-9 was caused by $\mathrm{ZnO}$. From the above information from the XRD patterns, it was supported that a good degree of orderliness of the vehicle as well as an appropriate amount of $\mathrm{ZnO}$ could help $\mathrm{ZnO}$ form a wurtzite structure on mesoporous silica.
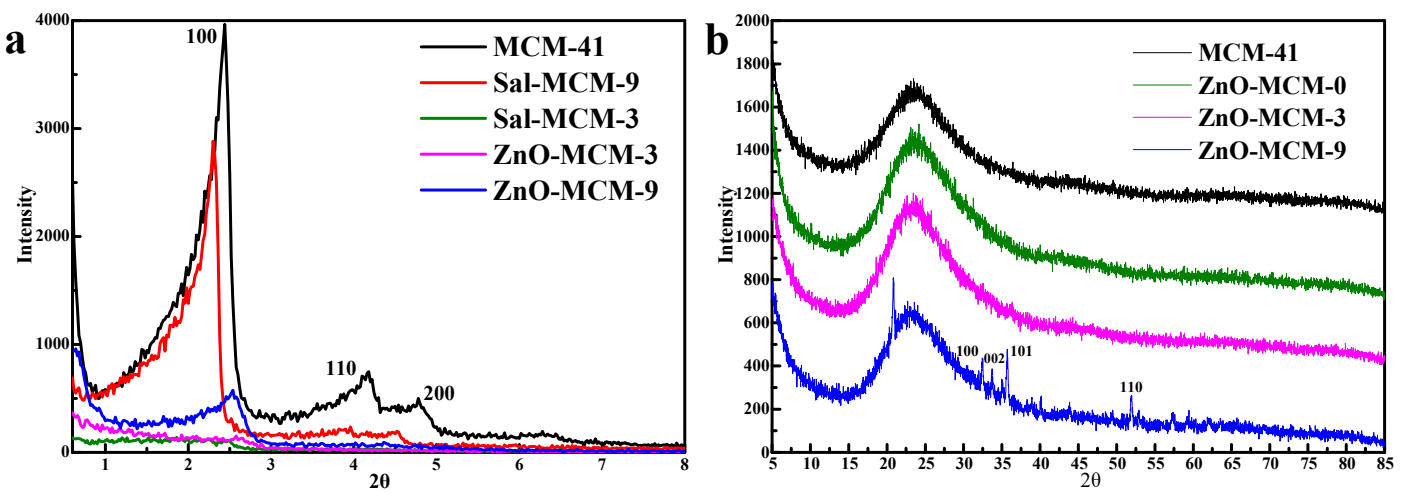

Figure 3. Low-X-ray diffraction patterns (XRD) (a) and Wide-XRD (b) patterns of MCM-41, Sal-MCM, and $\mathrm{ZnO}-\mathrm{MCM}$.

As listed in Table 2, the zeta potential of Sal-MCM-3 shifted from -35.38 to $40.08 \mathrm{mV}$, owing to the positive ions from the nitric of salicylaldimine [47]. The result proved that the surface of MCM-41 was modified with salicylaldimine. Table 2 also shows that the zeta potential of ZnO-MCM-3 shifted from -35.38 to $-23.08 \mathrm{mV}$. It proved that positively charged $\mathrm{ZnO}$ nanoparticles could partly neutralize the negative electric charges on the MCM-41 surface. However, Hassan [48] found that after the ZnO was supported on MCM-41, the material showed a positive zeta potential, which was about $9.3 \mathrm{mV}$. According to the detection mechanism of zeta potential, usually the electric potential detected by the machine was from the electrostatic field of the surface of the nanoparticles [49]. This confirmed that most of the $\mathrm{ZnO}$ nanoparticles were loaded in the channels of MCM-41 and only a small part of ZnO was loaded on the outside surface, which could also be proved from the change of pore diameter shown in Table 1.

Table 2. Zeta potential of MCM-41, Sal-MCM, and ZnO-MCM.

\begin{tabular}{cccc}
\hline Materials & MCM-41 & Sal-MCM-3 & ZnO-MCM-3 \\
\hline Zeta Potential $(\mathrm{mV})$ & -35.38 & 40.08 & -23.08 \\
\hline
\end{tabular}

Figures 4 and 5 depict the SEM and TEM images of MCM-41, Sal-MCM, ZnO-MCM-0, and $\mathrm{ZnO}-\mathrm{MCM}-9$. As shown, the regular hexagonal pore structure was well-maintained without agglomeration after the modification of salicylaldimine or the load of ZnO. Both Sal-MCM and $\mathrm{ZnO}-\mathrm{MCM}$ showed a rough shell structure on the external surface with many circular particles due to the introduction of salicylaldimine and $\mathrm{ZnO}$. The surface of $\mathrm{ZnO}-\mathrm{MCM}-9$ (Figure $4 \mathrm{~d}$ ) was rougher than that of ZnO-MCM-0 (Figure 4c), indicating that salicylaldimine could help the vehicles adsorb more zinc ions and, thus, more $\mathrm{ZnO}$ would form. Comparing the wurtzite form of nano $\mathrm{ZnO}$ showed by WXRD to the spherical form nanoparticles on the surface of ZnO-MCM-9, it was obvious that the wurtzite shaped $\mathrm{ZnO}$ were formed in the channels instead of the outside surface of MCM- 41 . This proved that the shape of $\mathrm{ZnO}$ nanoparticles could be controlled by the changeable channels of mesoporous silica, while those $\mathrm{ZnO}$ nanoparticles grown on the outside surface could not form in the same shape due to the lack of restrictions. Materials in Figure 5 all presented in the parallel lattice fringes structure [50] and corresponded to (100) crystal face, which showed the highest peak in Low-XRD. 


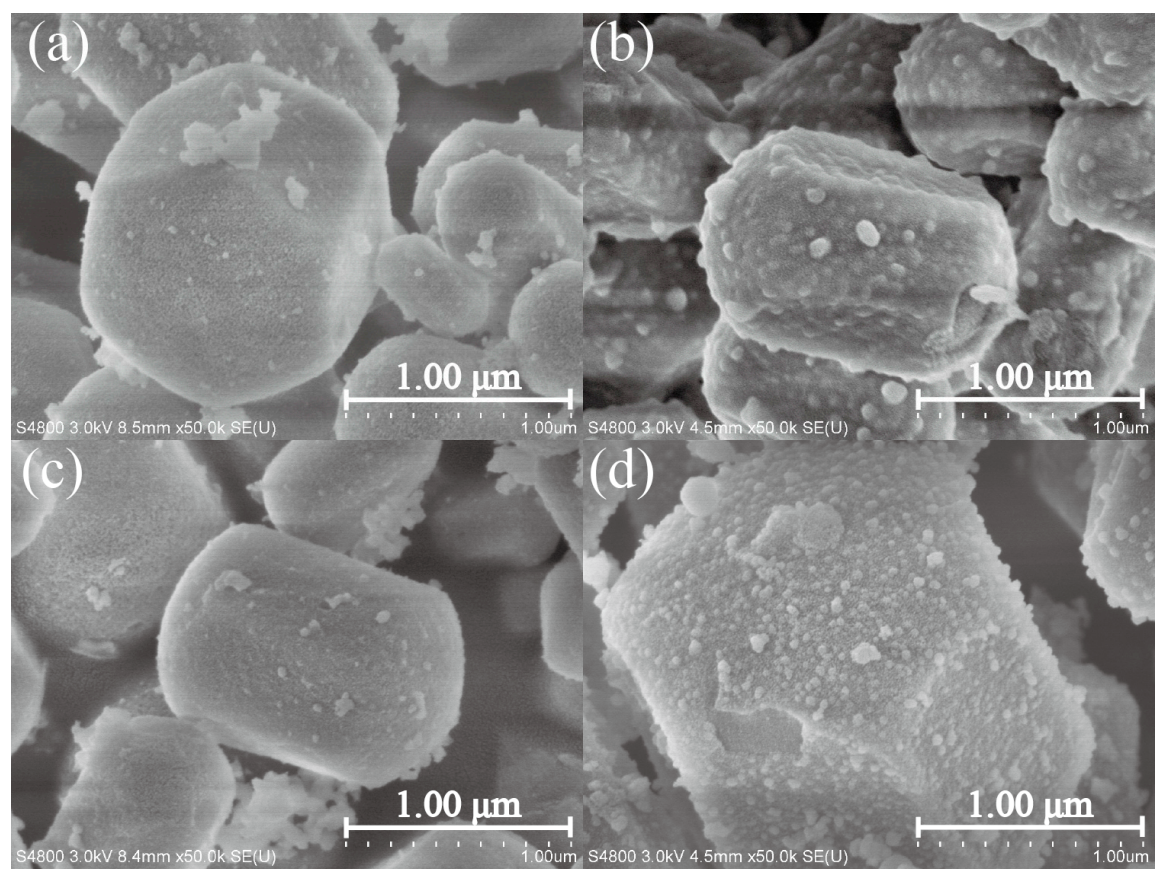

Figure 4. Scanning Electron Microscope (SEM) images of MCM-41 (a); Sal-MCM (b); ZnO-MCM-0 (c); and $\mathrm{ZnO}-\mathrm{MCM}-9$ (d).

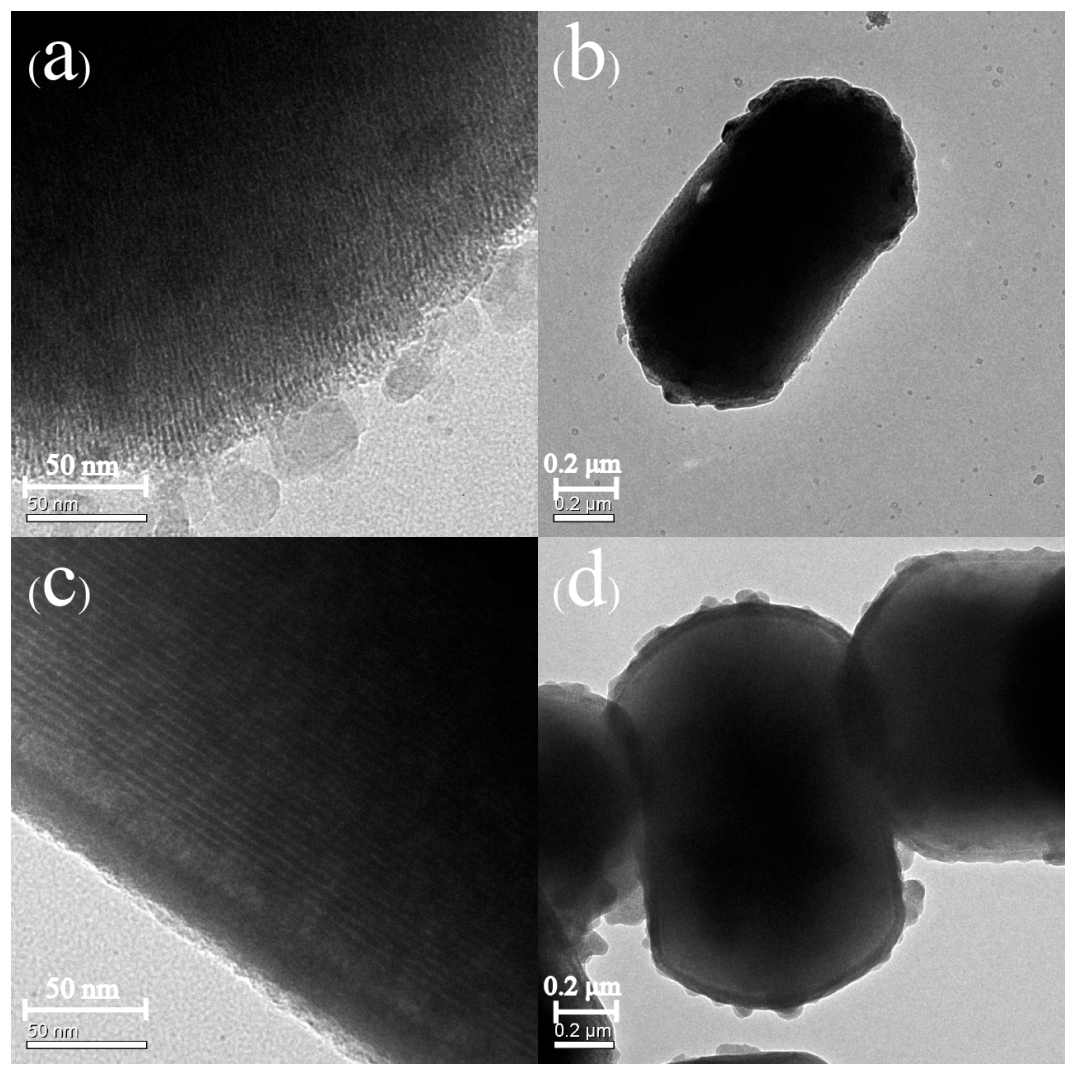

Figure 5. Cont. 


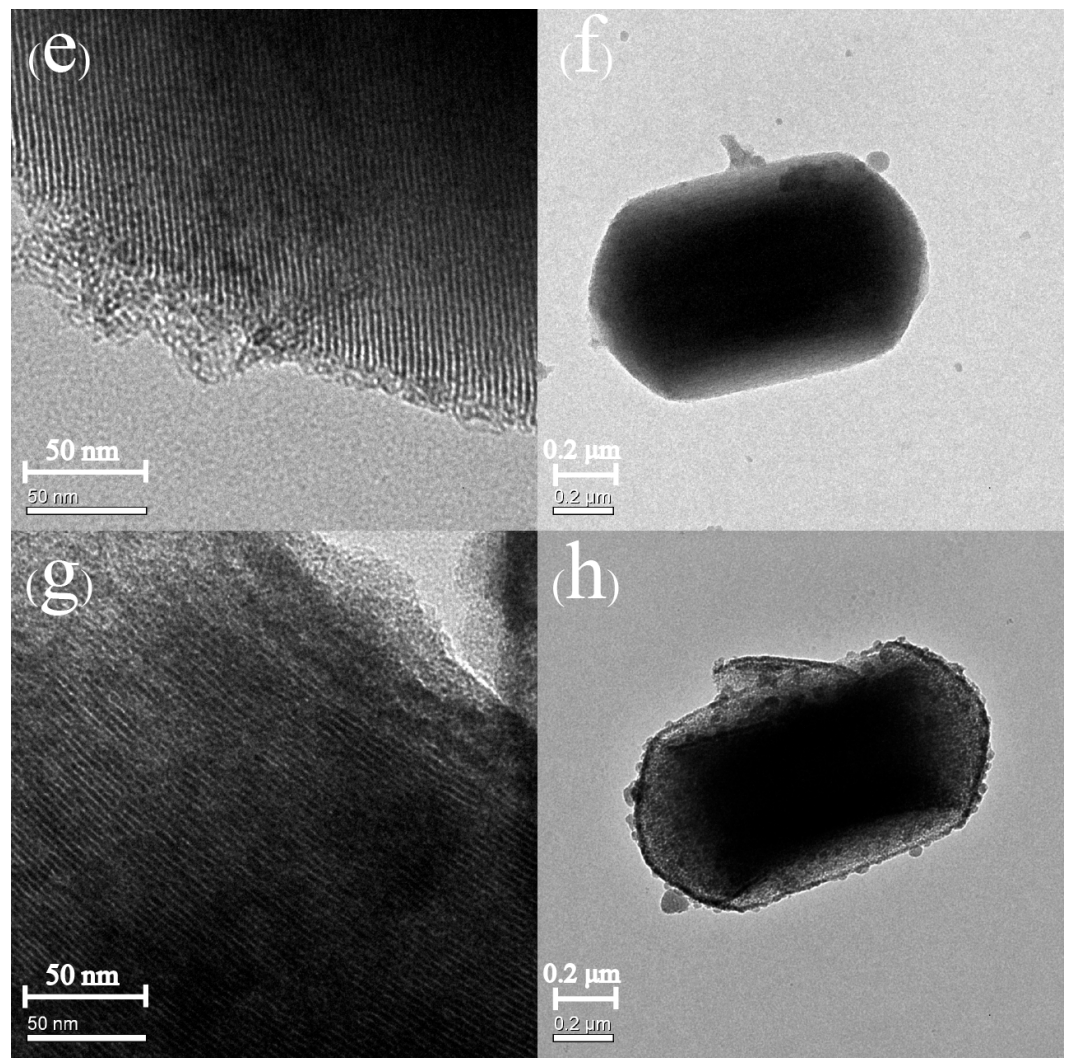

Figure 5. Transmission electron microscopy (TEM) images of MCM-41 (a,b), Sal-MCM (c,d), ZnO-MCM-0 (e,f), and ZnO-MCM-9 (g,h).

As seen in Figure 6, the XPS analysis was carried out to investigate the nanoparticle composition. In Figure 6a, it was observed that the binding energy regions positioned at $1022 \mathrm{eV}$ and $1045 \mathrm{eV}$ were assigned to $\mathrm{Zn} 2 \mathrm{p}_{3 / 2}$ and $\mathrm{Zn} 2 \mathrm{p}_{1 / 2}$, respectively [51], from the spectrum lines of both of the ZnO-MCM-3 and ZnO-MCM-9. Zn/Sal-MCM-3 and Zn/Sal-MCM-9 showed two peaks of Zn 2p at $1021 \mathrm{eV}$ and $1044 \mathrm{eV}$, respectively, which means that the zinc ions were coordinated with salicylaldimine. After the formation of $\mathrm{ZnO}$, the peak at $1044 \mathrm{eV}$ of $\mathrm{Zn} \mathrm{2p_{1/2 }}$ was more obvious. Meanwhile, the peak at $1021 \mathrm{eV}$ shifted positively to $1022 \mathrm{eV}$, due to the coordination bonds between zinc ions and salicylaldimine being replaced by the ionic bonds between the zinc atoms and oxygen atoms. On the one hand, the spectrum of $\mathrm{ZnO}-\mathrm{MCM}-0$ showed no special difference from that of MCM-41, while the spectrum lines of ZnO-MCM-3 and ZnO-MCM-9 were distinctly different from those of Sal-MCM-3 and Sal-MCM-9. On the other hand, for ZnO-MCM-0, its atomic concentration was 0.39, while $\mathrm{ZnO}-\mathrm{MCM}-3$ and $\mathrm{ZnO}-\mathrm{MCM}-9$ showed the atomic concentrations of 2.03 and 1.27, respectively (Table 3 ). These results confirmed that the more $\mathrm{ZnO}$ was loaded on MCM-41, the more obvious the peaks would be. It could be concluded that the modification of salicylaldimine does help to catch more zinc ions due to its strong coordination function. From Figure 7, we also found that the binding energy of the $\mathrm{Zn} 3 \mathrm{~d}$ electron in $\mathrm{ZnO}-\mathrm{MCM}$ is $11.58 \mathrm{eV}, 1.93 \mathrm{eV}$ higher than that of pure $\mathrm{ZnO}$, which indicates the formation of $\mathrm{Si}-\mathrm{O}-\mathrm{Zn}$ bond. This proved that, after the calcination, the interaction between $\mathrm{ZnO}$ and the silica matrix is the $\mathrm{Si}-\mathrm{O}-\mathrm{Zn}$ bond [39].

Figure $6 \mathrm{~b}$ exhibits the binding energy spectrum line of $\mathrm{N} 1 \mathrm{~s}$. A positive shift of $\mathrm{Zn} / \mathrm{Sal}-\mathrm{MCM}-3$ was observed, which showed that the peak value of $399.44 \mathrm{eV}$ moved to $400.14 \mathrm{eV}$. It was proposed that the electron transfer from nitrogen to zinc ions should be responsible for this result [52]. It proved that the coordination between the salicylaldimine and zinc ions was successfully formed. 

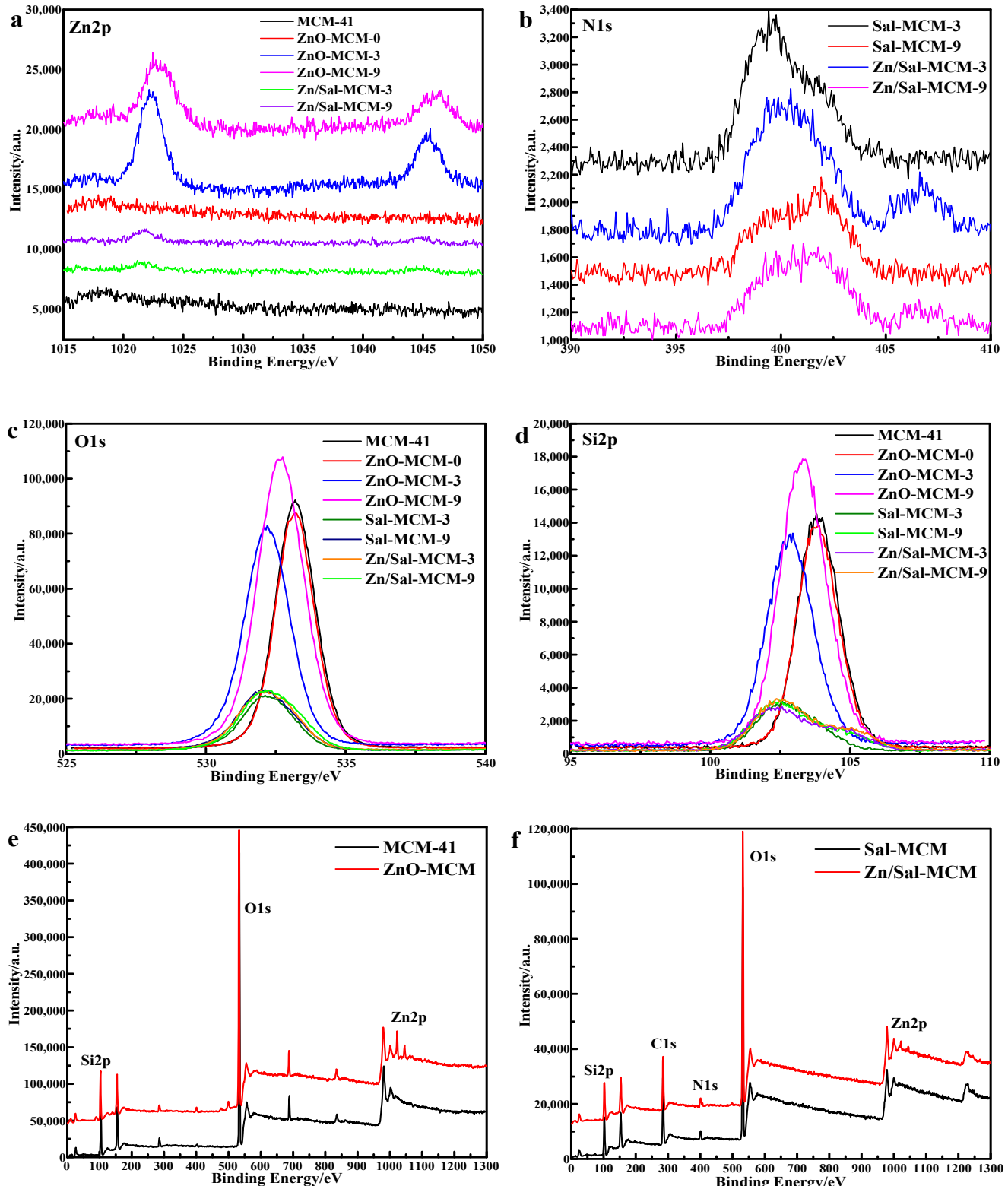

Figure 6. X-ray photo electron spectroscopy (XPS) of Zn 2p (a); N 1s (b); O 1s (c); Si 2p (d); survey (e,f) ofMCM-41, Sal-MCM, and ZnO-MCM.

Table 3. Binding energy and atomic of MCM-41, Sal-MCM, Zn/Sal-MCM, and ZnO-MCM.

\begin{tabular}{ccccccc}
\hline \multirow{2}{*}{ Material } & \multicolumn{4}{c}{ BE/eV } & \multicolumn{3}{c}{ Atomic/\% } \\
\cline { 2 - 7 } & Zn 2p & N 1s & Si 2p & O 1s & Zn 2p & Zn 2p3s \\
\hline MCM & - & - & 103.83 & 533.19 & - & - \\
Sal-MCM-3 & - & 399.44 & 102.63 & 532.20 & - & - \\
Sal-MCM-9 & - & 401.87 & 102.47 & 532.09 & - & - \\
Zn/Sal-MCM-3 & 1021.26 & 400.14 & 102.40 & 532.17 & - & 0.334 \\
Zn/Sal-MCM-9 & 1021.75 & 401.14 & 102.54 & 532.24 & - & 0.415 \\
ZnO-MCM-0 & 1017.90 & - & 103.81 & 533.18 & 0.39 & - \\
ZnO-MCM-3 & 1022.27 & - & 102.84 & 532.19 & 2.03 & - \\
ZnO-MCM-9 & 1022.90 & - & 103.29 & 532.67 & 1.27 & - \\
\hline
\end{tabular}




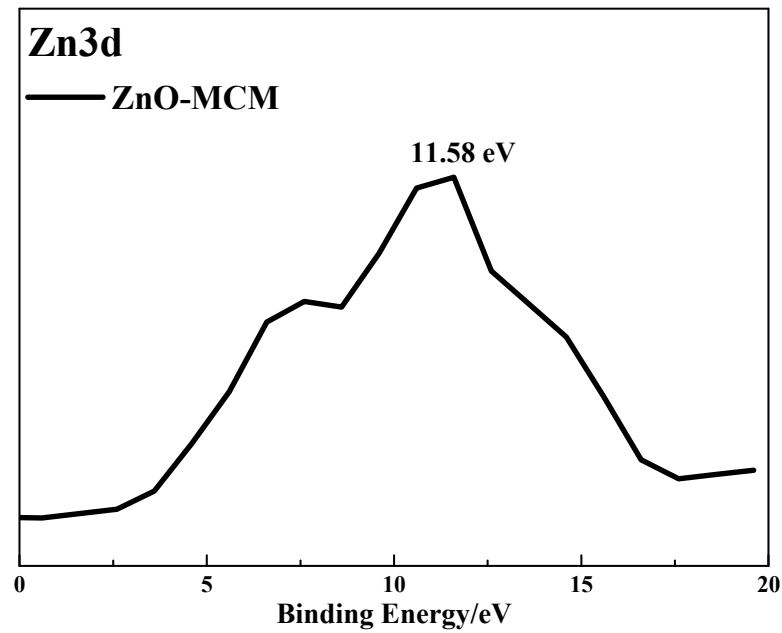

Figure 7. XPS of $\mathrm{Zn} 3 \mathrm{~d}$ of $\mathrm{ZnO}-\mathrm{MCM}$.

In Figure $6 \mathrm{c}$, all the binding energy peaks of $\mathrm{O} 1 \mathrm{~s}$ were symmetrical, which was different from previous reports [50] that indicated that only one chemical state for the oxygen species existed. For MCM-41, a peak centered at $533.19 \mathrm{eV}$ was definitely from the result of the oxygen atoms of MCM-41. Those energy peaks of $\mathrm{O} 1 \mathrm{~s}$, excluding that of $\mathrm{ZnO}-\mathrm{MCM}-0$, took a negative shift in varying degrees after the modification of salicylaldimine or $\mathrm{ZnO}$. This means that the modification of chemical groups or metal oxides would disturb the electron distribution of the surface of the vehicles. After the $\mathrm{ZnO}$ formed on the MCM-41, the electron intensity of $\mathrm{O} 1 \mathrm{~s}$ also increased, when compared to those of Sal-MCM-3 and Sal-MCM-9. It could be suggested that the zinc ions were transformed into $\mathrm{ZnO}$ because during this process, oxygen atoms would combine with zinc atoms, resulting in the increase of intensity of $\mathrm{O}$ 1s. In Figure 6d, the same change trend was also observed from the binding energy spectrum of $S i$ 2p, which could also be attributed to the similar reason. The overall XPS spectrum of MCM-41, ZnO-MCM, Sal-MCM, and Zn/Sal-MCM are shown in Figure 6e,f. All of the spectrum results confirmed that $\mathrm{ZnO}$ was successfully loaded onto MCM- 41 .

The UV-vis DRS of the nano-zinc oxide, mesoporous silica, and ZnO-MCM samples are shown in Figure 8. The adsorption band edge at $372 \mathrm{~nm}$ for $\mathrm{ZnO}-\mathrm{MCM}$ suggests the presence of $\mathrm{ZnO}$ particles [6]. Compared with $\mathrm{ZnO}$, a red shift of the adsorption band edge was observed, which can be ascribed to the well-known quantum size effect [53]. The wide absorption band from 250 to $372 \mathrm{~nm}$ observed in the $\mathrm{ZnO}-\mathrm{MCM}$ sample might be due to the formation of one-dimensional array inside the mesoporous silica, which is expected for these types of crystal growth [39]. Based on the maximum absorption wavelength, the band gap of $\mathrm{ZnO}$ nanoparticles supported on mesoporous silica was calculated to be $3.33 \mathrm{eV}$ according to the relation $E_{\mathrm{bg}}=1240 / \lambda_{\max }$, while the band gap of pure nano-zinc oxide was $3.50 \mathrm{eV}$ [54]. This means that the photocatalytic performance of $\mathrm{ZnO}$ was improved by being supported on mesoporous silica. 


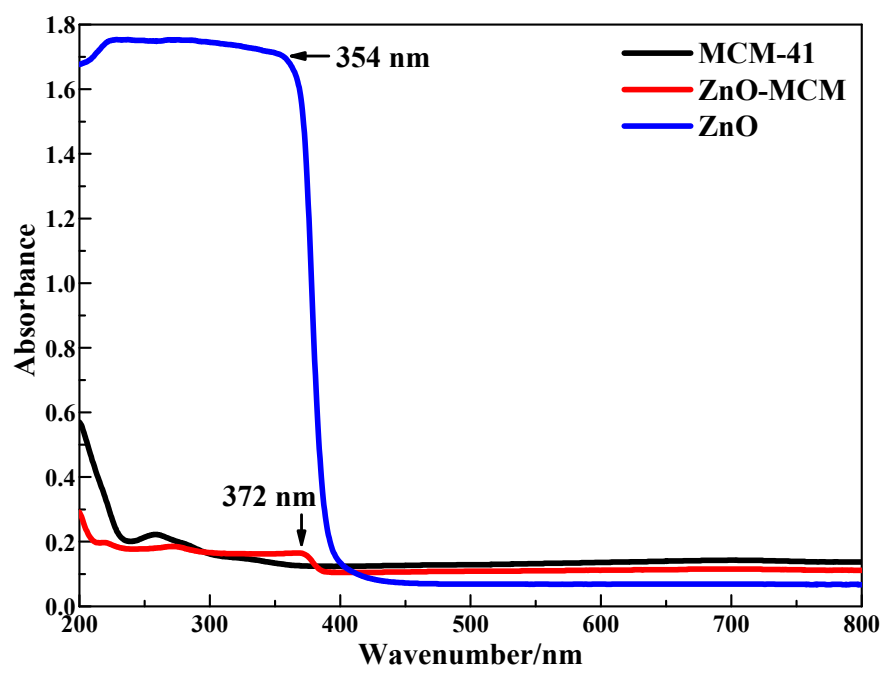

Figure 8. Diffuse reflectance UV-vis spectra of MCM-41, ZnO-MCM, and ZnO.

As shown in Figure 9, ZnO-MCM-3 and ZnO-MCM-9 were subjected to TGA to obtain the thermal stability information. For both ZnO-MCM-3 and ZnO-MCM-9, the loss in mass from $40{ }^{\circ} \mathrm{C}$ to $100{ }^{\circ} \mathrm{C}$ was due to the elimination of the crystallization water and residual physically adsorbed water on the surface of the channels [55]. The final residues of ZnO-MCM-3 and ZnO-MCM-9 were 86\% and 91\%, respectively, which showed that there were more nano zinc oxides supported on ZnO-MCM-3 than that of $\mathrm{ZnO}-\mathrm{MCM}-9$. It also proved that the more salicylaldimine was grafted on MCM-41, the more zinc ions would be coordinated and thus, more nano zinc oxides would form. According to the previous literature [56], the $\mathrm{ZnO}$ transformed into $\mathrm{Zn}_{2} \mathrm{SiO}_{4}$ began from 650 to $800{ }^{\circ} \mathrm{C}$ due to the reaction between $\mathrm{ZnO}$ and $\mathrm{SiO}_{2}$. However, in this work, the TG curves did not show an obvious sudden heat loss step at this temperature range and only a slow loss of weight during 100 to $800{ }^{\circ} \mathrm{C}$ was observed. It is supposed that the transformation of this material began at $100{ }^{\circ} \mathrm{C}$ and only a fraction of $\mathrm{ZnO}$ transform. Further research on this phenomenon will be undertaken in our future work.

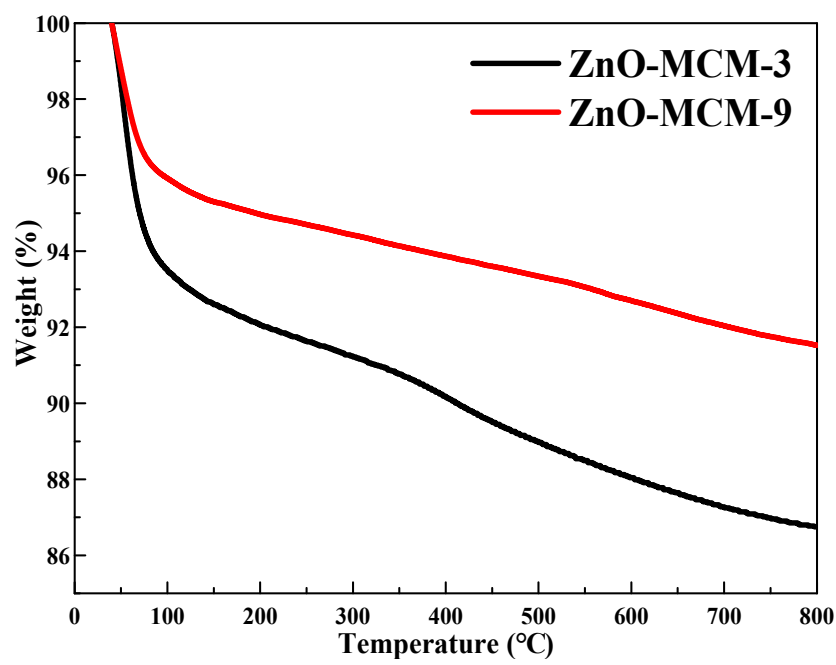

Figure 9. Thermogravimetry (TGA) curves of ZnO-MCM-3 and ZnO-MCM-9.

\subsection{Degradation of $M O$}

Figure 10 shows the photocatalytic activity of the as-prepared ZnO-MCM-0, ZnO-MCM-3, and $\mathrm{ZnO}-\mathrm{MCM}-9$ nanoparticles. The photodegradation of the $\mathrm{MO}$ was investigated in deionized water under ultraviolet irradiation. The MO solution without adding the as-prepared nanoparticles 
was chosen for comparison. The degradation process can be divided into two parts. During $45 \mathrm{~min}$, the double effect of adsorption and degradation of ZnO-MCM-9 and ZnO-MCM-3 made the concentration of $\mathrm{MO}$ rapidly decline by $54 \%$ and $45 \%$, respectively. From the 45 min to the end, the degradation rate caused by ZnO-MCM-3 was faster than that of ZnO-MCM-9. This could be indicated that in the first process of photocatalytic degradation, the surface area played a dominant role, while in the second process, the amount of $\mathrm{ZnO}$ loaded on MCM-41 dominated the degradation according to the zinc atomic weight of ZnO-MCM-3, which was more than that of ZnO-MCM-9 while the BET surface of ZnO-MCM-3 was smaller. Furthermore, the degree of orderliness as well as the crystallinity of the zinc oxide did not show any significant influence on the photocatalytic efficiency of $\mathrm{ZnO}-\mathrm{MCM}$. As a result, it took approximately $120 \mathrm{~min}$ to reduce the $\mathrm{MO}$ concentration using ZnO-MCM-3, while an additional $30 \mathrm{~min}$ was required with the use of ZnO-MCM-9. The pure MO degraded approximately 35\% after $200 \mathrm{~min}$, which implied that without ZnO-MCM, ultraviolet radiation only caused negligible degradation to $\mathrm{MO}$.
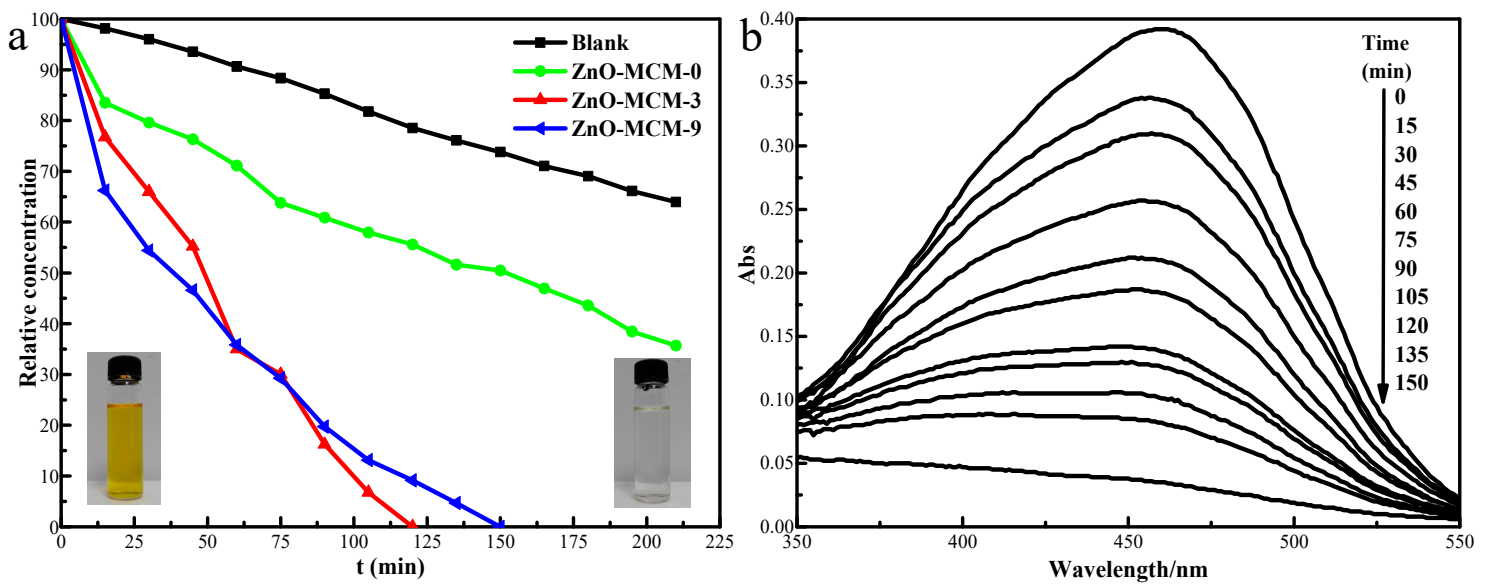

Figure 10. Photodegradation of MO under UV light using ZnO-MCM-0, ZnO-MCM-3 and ZnO-MCM-9 (a); and UV-Vis absorbance spectra of $\mathrm{MO}(\mathbf{b})$.

The two photos inset in Figure 10a reflect the obvious change in the color of the MO solution with the addition of $\mathrm{ZnO}-\mathrm{MCM}$ and the ultraviolet adsorption spectrum was used to confirm the degradation of MO. The color changed from orange to colorless in $150 \mathrm{~min}$ with the use of ZnO-MCM under UV light, and the characteristic peak at $463 \mathrm{~nm}$ for the absorption became weaker and disappeared in the final. This observation indicated that ZnO-MCM would accelerate the degradation of MO.

\subsection{Degradation Kinetics Study}

According to previous reports [39,50,57,58], a pseudo-second-order model (Equation (4)) [59] and pseudo-first-order model (Equation (3)) [60-62] evolved from the Langmuir-Hinshelwood mechanism (L-H model, Equation (2)) [63-65] can be applied to describe the photocatalytic degradation process of the organic dye reaction at the liquid-solid interface [66]. All the equations were displayed as follows:

$$
r=\frac{d C}{d t}=\frac{K_{r} K_{s} C}{1+K_{s} C_{o}}
$$

At a low initial concentration of MO, Equation (2) can be transformed into Equation (3).

$$
\ln \left(\frac{C_{o}}{C_{t}}\right)=K_{a p p} t
$$




$$
\frac{1}{C_{t}}=K t+\frac{1}{C_{o}}
$$

where $C_{o}$ and $C_{t}$ represent the concentration at the initial and treatment process time. $K_{s}$ and $K_{r}$ are the adsorption rate and reaction rate, respectively. $K_{a p p}$ and $K$ are the apparent pseudo-first-order and second-order rate constants, respectively.

The data of the MO degradation were fitted to a pseudo-first-order model and a pseudo-second-order model (Figure 11). The $\mathrm{R}$ values and constants of the two models are listed in Table 4. It was obvious that the pseudo-first-order model was more suitable than the pseudo-second-order model for the MO degradation. For ZnO-MCM-0, ZnO-MCM-9, and $\mathrm{ZnO}-\mathrm{MCM}-3$, the $K_{a p p}$ values were $0.00565,0.01816$ and 0.02491 , respectively, which indicated that the degradation rate was increasingly faster as the amount of $\mathrm{ZnO}$ increased.
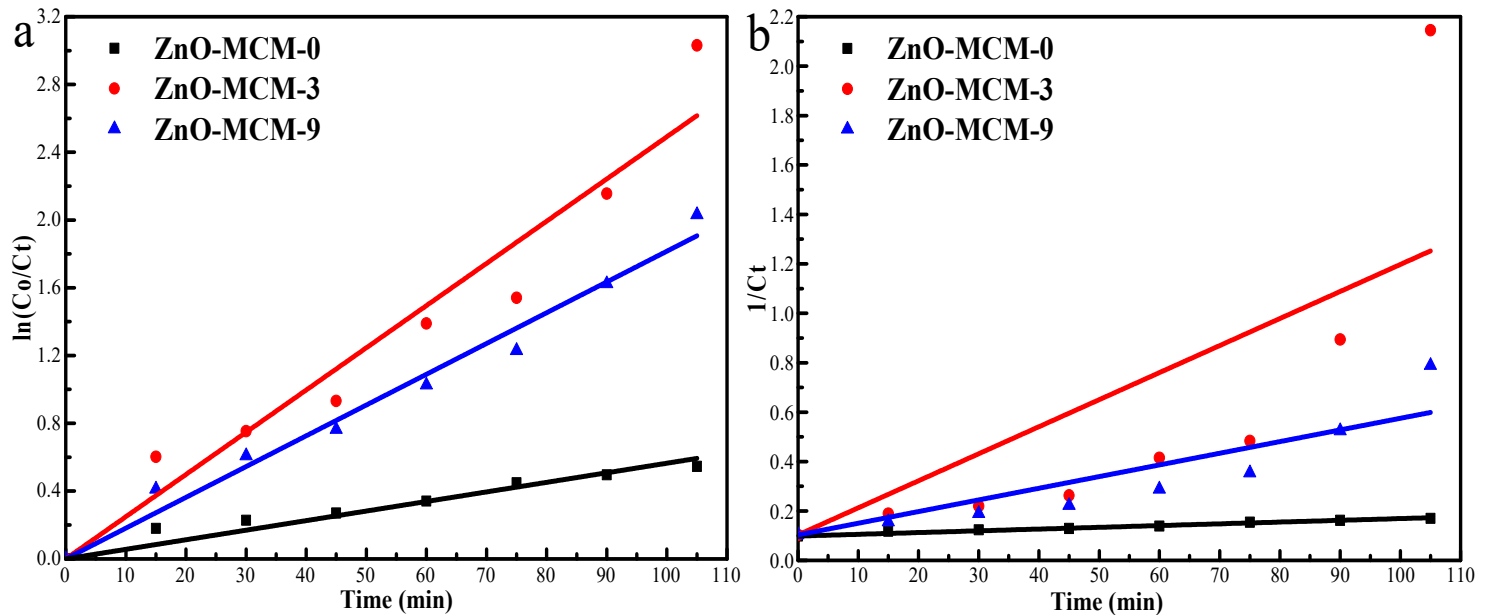

Figure 11. Photodegradation kinetics of MO using the pseudo-first-order model (a); and the pseudo-second-order model (b).

Table 4. Fitting results of the photodegradation of MO.

\begin{tabular}{|c|c|c|}
\hline Kinetic Models & Fitting Equation & $R^{2}$ \\
\hline \multirow{3}{*}{ pseudo first-order } & \multirow{3}{*}{$\ln \frac{C_{o}}{C_{t}}=\left\{\begin{array}{l}0.02491 t ; \mathrm{ZnC} \\
0.01816 t ; \mathrm{ZnC}\end{array}\right.$} & 0.98225 \\
\hline & & 0.97787 \\
\hline & & 0.99306 \\
\hline \multirow{3}{*}{ pseudo second-order } & $0.0007 t+0.09882 ; \mathrm{ZnO}-\mathrm{MCM}-0$ & 0.99913 \\
\hline & $\frac{1}{C_{t}}=\left\{\begin{array}{l}0.01094 t+0.10335 ; \mathrm{ZnO}-\mathrm{MCM}-3 \\
\end{array}\right.$ & 0.74946 \\
\hline & \begin{tabular}{l|l} 
& $0.00472 t+0.10335 ; \mathrm{ZnO}-\mathrm{MCM}-9$
\end{tabular} & 0.93623 \\
\hline
\end{tabular}

\subsection{Degradation Mechanism}

A possible mechanism of the degradation behavior would help to better understand the photocatalysis result (Scheme 2). As previous reports have depicted [67], irradiation with a suitable UV-light source whose band gap energy is smaller than its photon energy would activate the photocatalyst [68]. When a photon is caught by zinc oxide, it facilitates an electron transfer from the valence band to the conduction band. At this moment, an electron-hole pair emerges. These electron-hole pairs migrate to the surface of $\mathrm{ZnO}$ and start to oxidize and reduce the $\mathrm{MO}$ molecules absorbed on the outside surface or in the channels of the ZnO-MCM [69]. The surface hydroxyl groups acquire the holes and strongly oxidize to form hydroxyl radicals, which are generated in this process. At the same time, the combined materials, which include the aqueous solution, the oxide and the oxide radicals, also produce hydroxyl radicals. Ultimately, hydroxyl radicals generated by 
these two processes allow the oxidation of the $\mathrm{MO}$ dye absorbed on the surface of $\mathrm{ZnO}$, leading to the formation of ammonium, nitrate ion, sulfate, and $\mathrm{CO}_{2}$.

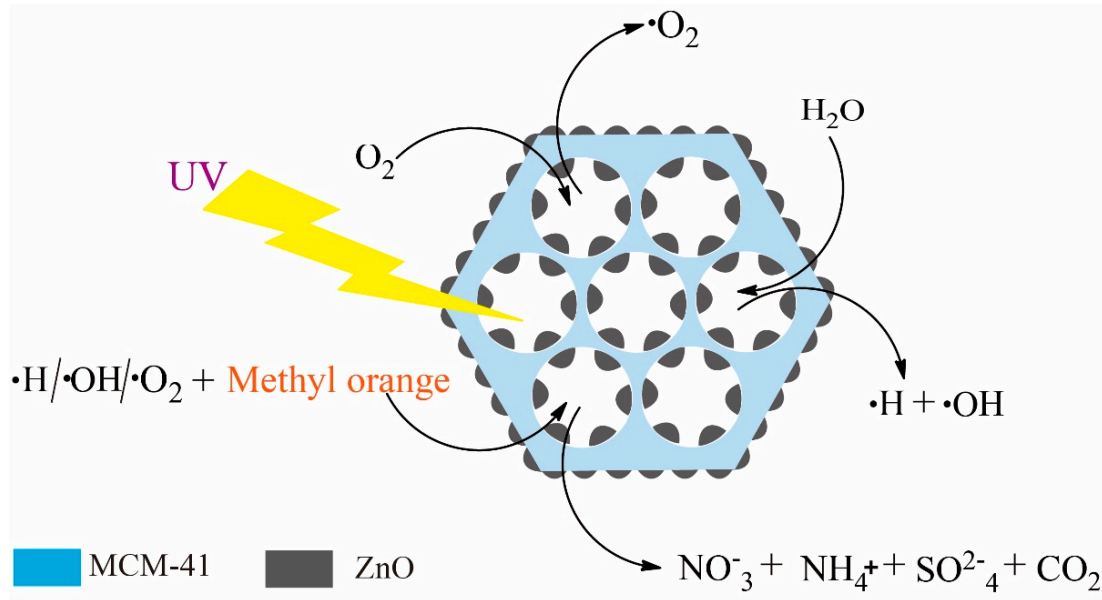

Scheme 2. Schematic illustration of degradation mechanism.

\subsection{Reusability Performance}

As shown in Figure 12, Tables 5 and 6, after six cycles, ZnO-MCM-3 was still effective in the photodegradation of $\mathrm{MO}$, remaining above $70 \%$. The decrease in the photocatalytic activity might be due to the loss of zinc, the change of pore structure and the reduction of surface area. These change of parameters not only resulted in the change of the amount of active oxygen produced by $\mathrm{ZnO}-\mathrm{MCM}-3$, but also brought a decrease of the contact area between ZnO-MCM-3 and MO. All of the factors ultimately affected the photodegradation efficiency.
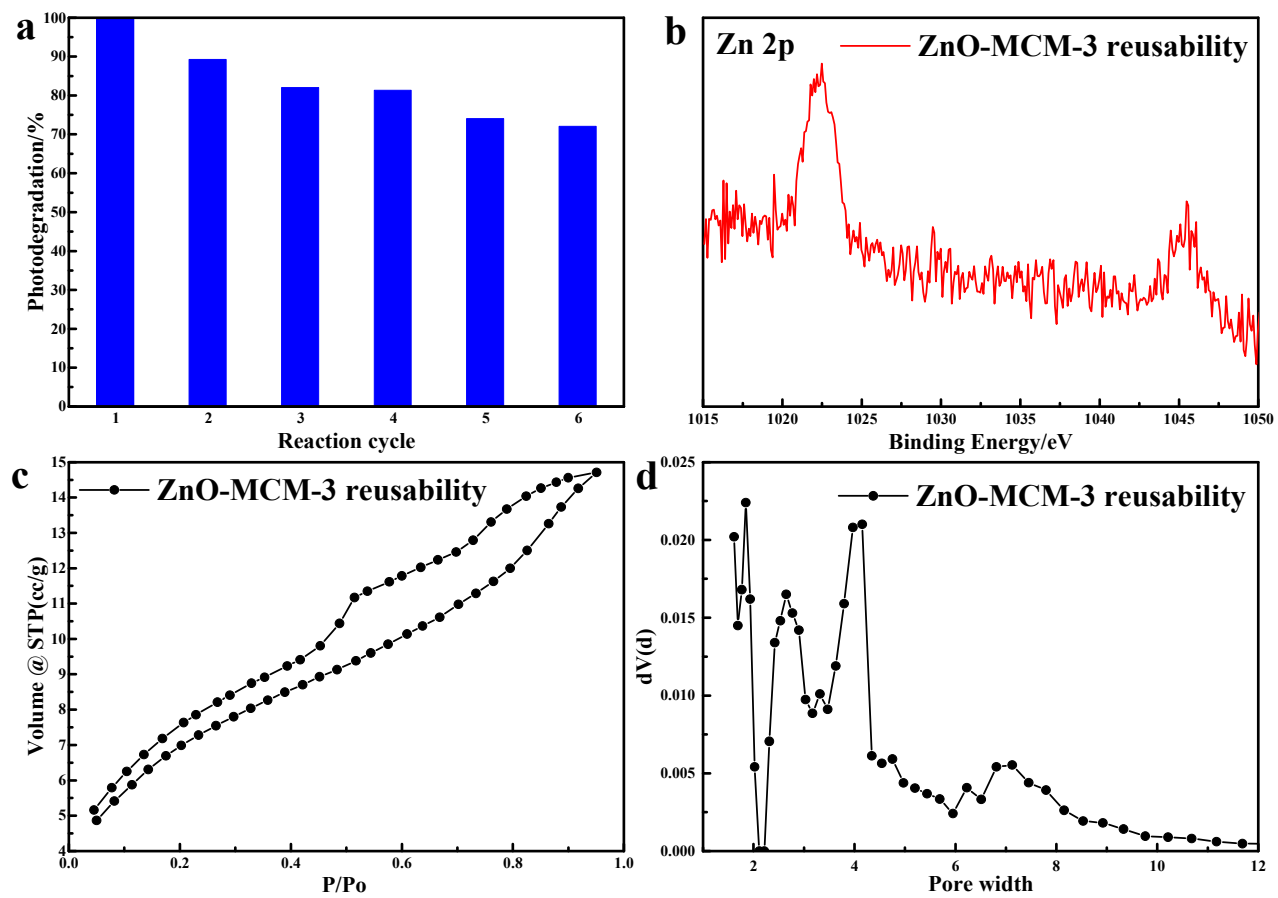

Figure 12. Reusability of ZnO-MCM-3 toward the photodegradation of $\mathrm{MO}$ (a), XPS of Zn 2p (b), $\mathrm{N}_{2}$ adsorption/desorption isotherms (c) and pore size distribution (d). 
Table 5. The pore structural parameters of ZnO-MCM-3 after six photodegradation cycles of MO.

\begin{tabular}{cccc}
\hline Materials & Surface Area $\left(\mathbf{m}^{2} / \mathbf{g}\right)$ & Pore Diameter Dv $(\mathbf{n m})$ & Pore Volume $\left(\mathbf{m}^{\mathbf{3}} / \mathbf{g}\right)$ \\
\hline ZnO-MCM-3 & 739.543 & 2.180 & 0.547 \\
Reusable ZnO-MCM-3 & 420.100 & 3.043 & 0.233 \\
\hline
\end{tabular}

Table 6. Binding energy and atomic of ZnO-MCM-3 after six photodegradation cycles of MO.

\begin{tabular}{cccccc}
\hline \multirow{2}{*}{ Material } & \multicolumn{3}{c}{ BE/eV } & \multicolumn{2}{c}{ Atomic/\% } \\
\cline { 2 - 6 } & Zn 2p & N 1s & Si 2p & O 1s & Zn 2p \\
\hline ZnO-MCM-3 & 1022.27 & - & 102.84 & 532.19 & 2.03 \\
Reusable ZnO-MCM-3 & 1022.37 & - & 102.92 & 531.89 & 0.63 \\
\hline
\end{tabular}

\section{Conclusions}

In this study, ZnO-MCM-3 and ZnO-MCM-9 with photodegradation properties were prepared by two steps. Zinc ions were introduced to MCM-41 by coordinating with salicylaldimine modified on mesoporous silica and then a high-temperature oxidation was undertaken to transform zinc ions into zinc oxide and remove the salicylaldimine. The characterization confirmed that during the wet impregnation, the coordination of salicylaldimine could help to adsorb more zinc ions so that more $\mathrm{ZnO}$ would load on mesoporous silica. The more salicylaldimine was grafted on MCM-41, the more zinc ions would be caught and more nano zinc oxide would form. The appearance of hierarchical tunnels proved that $\mathrm{ZnO}$ were loaded in the channels of MCM-41. Furthermore, a suitable grafted amount of salicylaldimine as well as a good degree of orderliness would help MCM-41 to make those nano $\mathrm{ZnO}$ loaded in the channels grow into wurtzite crystalline. However, due to the lack of restrictions, nano $\mathrm{ZnO}$ loaded on the outside surface of $\mathrm{MCM}-41$ were formed in spherical instead of wurtzite crystalline. The addition of $\mathrm{ZnO}-\mathrm{MCM}$ did enhance the degradation efficiency of $\mathrm{MO}$ under $\mathrm{UV}$ radiation. The degradation of $\mathrm{MO}$ was mainly controlled by two physical constants. The surface areas of the $\mathrm{ZnO}-\mathrm{MCM}$ played a dominant role in the first process while the loading amount of nano $\mathrm{ZnO}$ showed a more important role during the second process. Meanwhile, though the blocking effect of nano $\mathrm{ZnO}$ in the channels would reduce the orderliness of the vehicle, it was seen that this effect did not have much influence on the degradation efficiency. The pseudo-first-order model could be used to explain the photodegradation process. In brief, with the help of the coordination effect of the modified mesoporous silica, more metal ions will be adsorbed, so that more nano metal oxide will load on the mesoporous silica after the oxidization process. This method will make the mesoporous materials play a more significant role in the loading of nano metal oxide.

Author Contributions: Z.S. and X.Z. conceived and designed the experiments; Z.S. performed the experiment; Z.S.; H.Z. and X.Z. analyzed the data; H.X. and H.C. contributed the reagents/materials; C.F. offered analysis tools; Z.S.; H.Z. and X.Z. wrote/edited the paper.

Funding: This research was funded by National Natural Science Foundation of China (Grant No. 21576303, 21606262), Natural Science Foundation of Guangdong Province (Grant No. 2017A030311003), Science and Technology Program of Guangzhou, China (Grant No. 201604020054).

Conflicts of Interest: The authors declare no competing financial interest.

\section{References}

1. Lakshmi Kantam, M.; Kumar, K.B.S.; Sridhar, C. Nanocrystalline $\mathrm{ZnO}$ as an efficient heterogeneous catalyst for the synthesis of 5-Substituted $1 H$-Tetrazoles. Adv. Synth. Catal. 2005, 347, 1212-1214. [CrossRef]

2. Chen, H.; Tang, M.; Rui, Z.; Wang, X.; Ji, H. ZnO modified $\mathrm{TiO}_{2}$ nanotube array supported Pt catalyst for HCHO removal under mild conditions. Catal. Today 2016, 264, 23-30. [CrossRef]

3. Johar, M.A.; Afzal, R.A.; Alazba, A.A.; Manzoor, U. Photocatalysis and bandgap engineering using ZnO nanocomposites. Adv. Mater. Sci. Eng. 2015, 2015, 934587. [CrossRef] 
4. Hoseinzadeh, E.; Makhdoumi, P.; Taha, P.; Hossini, H.; Stelling, J.; Kamal, M.A.; Ashraf, G.M. A review on nano-antimicrobials: Metal nanoparticles, methods and mechanisms. Curr. Drug Metab. 2017, 18, 120-128. [CrossRef] [PubMed]

5. Koch, U.; Fojtik, A.; Henglein, H.W.A.A. Photochemistry of semiconductor colloids. Preparation of extremely small $\mathrm{ZnO}$ particles, fluorescence phenomena and size quantization effects. Chem. Phys. Lett. 1985, 122, 507-510. [CrossRef]

6. Lihitkar, P.B.; Violet, S.; Shirolkar, M.; Singh, J.; Srivastava, O.N.; Naik, R.H.; Kulkarni, S.K. Confinement of zinc oxide nanoparticles in ordered mesoporous silica MCM-41. Mater. Chem. Phys. 2012, 133, 850-856. [CrossRef]

7. Sowri Babu, K.; Ramachandra Reddy, A.; Sujatha, C.; Venugopal Reddy, K. Effect of Mg doping on photoluminescence of ZnO/MCM-41 nanocomposite. Ceram. Int. 2012, 38, 5949-5956. [CrossRef]

8. Lee, K.M.; Lai, C.W.; Ngai, K.S.; Juan, J.C. Recent developments of zinc oxide based photocatalyst in water treatment technology: A review. Water Res. 2016, 88, 428-448. [CrossRef] [PubMed]

9. Mishra, Y.K.; Adelung, R. ZnO Tetrapod Materials for Functional Applications. Mater. Today 2017. [CrossRef]

10. Yin, Q.; Qiao, R.; Li, Z.; Zhang, X.L.; Zhu, L. Hierarchical nanostructures of nickel-doped zinc oxide: Morphology controlled synthesis and enhanced visible-light photocatalytic activity. J. Alloys Compd. 2015, 618, 318-325. [CrossRef]

11. Tamaddon, F.; Moradi, S. Controllable selectivity in Biginelli and Hantzsch reactions using nano $\mathrm{ZnO}$ as a structure base catalyst. J. Mol. Catal. A Chem. 2013, 370, 117-122. [CrossRef]

12. Tamaddon, F.; Aboee, F.; Nasiri, A. ZnO nanofluid as a structure base catalyst for chemoselective amidation of aliphatic carboxylic acids. Catal. Commun. 2011, 16, 194-197. [CrossRef]

13. Gupta, M.; Paul, S.; Gupta, R.; Loupy, A. ZnO: A versatile agent for benzylic oxidations. Tetrahedron Lett. 2005, 46, 4957-4960. [CrossRef]

14. Bhuyan, D.; Saikia, M.; Saikia, L. ZnO nanoparticles embedded in SBA-15 as an efficient heterogeneous catalyst for the synthesis of dihydropyrimidinones via Biginelli condensation reaction. Microporous Mesoporous Mater. 2018, 256, 39-48. [CrossRef]

15. Hou, Y.; Abdullah, H.; Kuo, D.; Leu, S.; Gultom, N.S.; Su, C. A comparison study of $\mathrm{SiO}_{2} /$ nano metal oxide composite sphere for antibacterial application. Compos. Part B Eng. 2018, 133, 166-176. [CrossRef]

16. Qin, P.; Yang, Y.; Zhang, X.; Niu, J.; Yang, H.; Tian, S.; Zhu, J.; Lu, M. Highly efficient, rapid, and simultaneous removal of cationic dyes from aqueous solution using monodispersed mesoporous silica nanoparticles as the adsorbent. Nanomaterials 2018, 8, 4. [CrossRef] [PubMed]

17. Watermann, A.; Brieger, J. Mesoporous silica nanoparticles as drug delivery vehicles in cancer. Nanomaterials 2017, 7, 189. [CrossRef] [PubMed]

18. Wagner, T.; Haffer, S.; Weinberger, C.; Klaus, D.; Tiemann, M. Mesoporous materials as gas sensors. Chem. Soc. Rev. 2013, 42, 4036-4053. [CrossRef] [PubMed]

19. Jasiorski, M.; Leszkiewicz, A.; Brzeziński, S.; Bugla-Płoskońska, G.; Malinowska, G.; Borak, B.; Karbownik, I.; Baszczuk, A.; Stręk, W.; Doroszkiewicz, W. Textile with silver silica spheres: Its antimicrobial activity against Escherichia coli and Staphylococcus aureus. J. Sol-Gel Sci. Technol. 2009, 51, 330-334. [CrossRef]

20. Reinosa, J.J.; Leretb, P.; Álvarez-Docioa, C.M.; Del Campoa, A.D.; Fernándeza, J.F. Enhancement of UV absorption behavior in $\mathrm{ZnO}_{-} \mathrm{TiO}_{2}$ composites. Bol. Soc. Esp. Ceram. Vidr. 2016, 55, 55-62. [CrossRef]

21. Reinosaa, J.J.; Leretb, P.; Álvarez-Docioa, C.M.; Campoa, A.D.; Fernándeza, J.F. Hierarchical nano ZnO-micro $\mathrm{TiO}_{2}$ composites: High UV protection yield lowering photodegradation in sunscreens. Bol. Soc. Esp. Ceram. Vidr. 2018, 44, 2827-2834.

22. Zhou, W.Z. Mesoporous crystals of transition metal oxides. Solid State Phenom. 2008, 140, 37-46. [CrossRef]

23. Zhang, Y.; Xie, T.; Jiang, T.; Wei, X.; Pang, S.; Wang, X.; Wang, D. Surface photovoltage characterization of a $\mathrm{ZnO}$ nanowire array / CdS quantum dot heterogeneous film and its application for photovoltaic devices. Nanotechnology 2009, 20, 155707. [CrossRef] [PubMed]

24. Baxter, J.B.; Aydil, E.S. Dye-sensitized solar cells based on semiconductor morphologies with ZnO nanowires. Sol. Energy Mater. Sol. Cells 2006, 90, 607-622. [CrossRef]

25. Da'Na, E. Adsorption of heavy metals on functionalized-mesoporous silica: A review. Microporous Mesoporous Mater. 2017, 247, 145-157. [CrossRef]

26. Nasreen, S.; Urooj, A.; Rafique, U.; Ehrman, S. Functionalized mesoporous silica: Absorbents for water purification. Desalin. Water Treat. 2016, 57, 29352-29362. [CrossRef] 
27. Chouyyok, W.; Shin, Y.; Davidson, J.; Samuels, W.D.; Lafemina, N.H.; Rutledge, R.D.; Fryxell, G.E.; Sangvanich, T.; Yantasee, W. Selective removal of copper(II) from natural waters by nanoporous sorbents functionalized with chelating diamines. Environ. Sci. Technol. 2010, 44, 6390-6395. [CrossRef] [PubMed]

28. He, R.; Wang, Z.; Tan, L.; Zhong, Y.; Li, W.; Xing, D.; Wei, C.; Tang, Y. Design and fabrication of highly ordered ion imprinted SBA-15 and MCM-41 mesoporous organosilicas for efficient removal of $\mathrm{Ni}^{2+}$ from different properties of wastewaters. Microporous Mesoporous Mater. 2018, 257, 212-221. [CrossRef]

29. Zhang, W.; Shi, J.; Wang, L.; Yan, D. Preparation and Characterization of ZnO Clusters inside Mesoporous Silica. Chem. Mater. 2000, 12, 1408-1413. [CrossRef]

30. Chen, H. The preparation and photoluminescence properties of ZnO-MCM-41. Opt. Mater. 2004, 25, 79-84. [CrossRef]

31. Haggag, S.M.S.; Abdel-Hamid, I.A.M. A tridentate (O, N, O) donor Schiff base zinc(II) nano complex. J. Therm. Anal. Calorim. 2015, 119, 737-746. [CrossRef]

32. Mureseanu, M.; Reiss, A.; Stefanescu, I.; David, E.; Parvulescu, V.; Renard, G.; Hulea, V. Modified SBA-15 mesoporous silica for heavy metal ions remediation. Chemosphere 2008, 73, 1499-1504. [CrossRef] [PubMed]

33. Khalaji, A.D.; Nikookar, M.; Das, D. Co(III), Ni(II), and Cu(II) complexes of bidentate N,O-donor Schiff base ligand derived from 4-methoxy-2-nitroaniline and salicylaldehyde. J. Therm. Anal. Calorim. 2014, 115, 409-417. [CrossRef]

34. Li, H.; You, Z.; Zhang, C.; Yang, M.; Gao, L.; Wang, L. Zinc and thiocyanate-mediated oxazolidine ring formation in a trinuclear zinc(II) complex: Synthesis, structure, and properties. Inorg. Chem. Commun. 2013, 29, 118-122. [CrossRef]

35. Hoffmann, F.; Cornelius, M.; Morell, J.; Fröba, M. Silica-based mesoporous organic-inorganic hybrid materials. Angew. Chem. Int. Ed. 2006, 45, 3216-3251. [CrossRef] [PubMed]

36. Jantawasu, P.; Sreethawong, T.; Chavadej, S. Photocatalytic activity of nanocrystalline mesoporous-assembled $\mathrm{TiO}_{2}$ photocatalyst for degradation of methyl orange monoazo dye in aqueous wastewater. Chem. Eng. J. 2009, 155, 223-233. [CrossRef]

37. Rostamizadeh, S.; Nojavan, M. An environmentally benign multicomponent synthesis of some novel 2-Methylthio pyrimidine derivatives using MCM-41- $\mathrm{NH}_{2}$ as nanoreactor and nanocatalyst. J. Heterocycl. Chem. 2014, 51, 418-422. [CrossRef]

38. He, L.; Huang, Y.; Zhu, H.; Pang, G.; Zheng, W.; Wong, Y.; Chen, T. Cancer-targeted monodisperse mesoporous silica nanoparticles as carrier of ruthenium polypyridyl complexes to enhance theranostic effects. Adv. Funct. Mater. 2014, 24, 2754-2763. [CrossRef]

39. Jiang, Q.; Wu, Z.Y.; Wang, Y.M.; Cao, Y.; Zhou, C.F.; Zhu, J.H. Fabrication of photoluminescent ZnO/SBA-15 through directly dispersing zinc nitrate into the as-prepared mesoporous silica occluded with template. J. Mater. Chem. 2006, 16, 1536-1542. [CrossRef]

40. Pourdayhimi, P.; Koh, P.W.; Salleh, M.M.; Nur, H.; Lee, S.L. Zinc oxide nanoparticles-immobilized mesoporous hollow silica spheres for photodegradation of sodium dodecylbenzenesulfonate. Aust. J. Chem. 2016, 69, 790-797. [CrossRef]

41. Zhou, W.Z.; Zhao, D.Y.; Wan, Y. Ordered Mesoporous Molecular Sieve Materials; Liu, J.B., Ed.; Higher Education Press: Beijing, China, 2013.

42. Kang, J.; Park, J.; Kim, J.; Lee, C.; Kim, S. Surface functionalization of mesoporous silica MCM-41 with 3-aminopropyltrimethoxysilane for dye removal: Kinetic, equilibrium, and thermodynamic studies. Desalin. Water Treat. 2015, 57, 7066-7078. [CrossRef]

43. Budi Hartono, S.; Qiao, S.; Jack, K.; Ladewig, B.P.; Hao, Z.; Lu, G.M. Improving adsorbent properties of cage-like ordered amine functionalized mesoporous silica with very large pores for bioadsorption. Langmuir 2009, 25, 6413-6424. [CrossRef] [PubMed]

44. Moosavi, A.; Sarrafi, M.; Aghaei, A.; Hessari, F.A.; Keyanpour-Rad, M. Synthesis of mesoporous ZnO/SBA-15 composite via sonochemical route. Micro Nano Lett. 2012, 7, 130-133. [CrossRef]

45. Babu, K.S.; Reddy, A.R.; Sujatha, C.; Reddy, K.V. Effects of precursor, temperature, surface area and excitation wavelength on photoluminescence of $\mathrm{ZnO} /$ mesoporous silica nanocomposite. Ceram. Int. 2013, 39, 3055-3064. [CrossRef]

46. Jeong, B.; Kim, D.H.; Park, E.J.; Jeong, M.; Kim, K.; Seo, H.O.; Kim, Y.D.; Uhm, S. ZnO shell on mesoporous silica by atomic layer deposition: Removal of organic dye in water by an adsorbent and its photocatalytic regeneration. Appl. Surf. Sci. 2014, 307, 468-474. [CrossRef] 
47. Yantasee, W.; Lin, Y.; Fryxell, G.E.; Busche, B.J.; Birnbaum, J.C. Removal of heavy metals from aqueous solution using novel nanoengineered sorbents: Self-assembled carbamoylphosphonic acids on mesoporous Silica. Sep. Sci. Technol. 2003, 15, 3809-3825. [CrossRef]

48. Rakhshaei, R.; Namazi, H. A potential bioactive wound dressing based on carboxymethyl cellulose/ZnO impregnated MCM-41 nanocomposite hydrogel. Mater. Sci. Eng. C 2017, 73, 456-464. [CrossRef] [PubMed]

49. Bhattacharjee, S. DLS and zeta potential-What they are and what they are not? J. Control. Release 2016, 235, 337-351. [CrossRef] [PubMed]

50. Dai, P.; Yan, T.; Yu, X.; Bai, Z.; Wu, M. Two-solvent method synthesis of NiO/ZnO nanoparticles embedded in mesoporous SBA-15: Photocatalytic properties study. Nanoscale Res. Lett. 2016, 11, 226. [CrossRef] [PubMed]

51. Kaur, A.; Ibhadon, A.O.; Kansal, S.K. Photocatalytic degradation of ketorolac tromethamine (KTC) using Ag-doped ZnO microplates. J. Mater. Sci. 2017, 52, 5256-5267. [CrossRef]

52. Chen, H.Y.; Lin, Y.S.; Zhou, H.J.; Zhou, X.H.; Gong, S.; Xu, H. Synthesis and characterization of chlorpyrifos/copper(II) schiff base mesoporous silica with $\mathrm{pH}$ sensitivity for pesticide sustained release. J. Agric. Food Chem. 2016, 64, 8095-8102. [CrossRef] [PubMed]

53. Volokitin, Y.; Sinzig, J.; de Jongh, L.J.; Schmid, G.; Vargaftik, M.N.; Moiseevi, I.I. Quantum-size effects in the thermodynamic properties of metallic nanoparticles. Nature 1996, 384, 621. [CrossRef]

54. Tayebee, R.; Javadi, F.; Argi, G. Easy single-step preparation of ZnO nano-particles by sedimentation method and studying their catalytic performance in the synthesis of 2-aminothiophenes via Gewald reaction. J. Mol. Catal. A Chem. 2013, 368-369, 16-23. [CrossRef]

55. Raza, W.; Haque, M.M.; Muneer, M. Synthesis of visible light driven ZnO: Characterization and photocatalytic performance. Appl. Surf. Sci. 2014, 322, 215-224. [CrossRef]

56. Liu, C.; Lai, N.; Liou, S.; Chu, M.; Chen, C.; Yang, C. Deposition and thermal transformation of metal oxides in mesoporous SBA-15 silica with hydrophobic mesopores. Microporous Mesoporous Mater. 2013, 179, 40-47. [CrossRef]

57. Nekouei, F.; Nekouei, S. Comparative study of photocatalytic activities of $\mathrm{Zn}_{5}(\mathrm{OH})_{8} \mathrm{Cl}_{2} \cdot \mathrm{H}_{2} \mathrm{O}$ and $\mathrm{ZnO}$ nanostructures in ciprofloxacin degradation: Response surface methodology and kinetic studies. Sci. Total Environ. 2017, 601-602, 508-517. [CrossRef] [PubMed]

58. Assi, N.; Azar, P.A.; Tehrani, M.S.; Husain, S.W. Studies on photocatalytic performance and photodegradation kinetics of zinc oxide nanoparticles prepared by microwave-assisted sol-gel technique using ethylene glycol. J. Iran. Chem. Soc. 2016, 13, 1593-1602. [CrossRef]

59. Keng, P.; Lee, S.; Ha, S.; Hung, Y.; Ong, S. Cheap materials to clean heavy metal polluted waters. In Green Materials for Energy, Products and Depollution; Lichtfouse, E., Ed.; Springer Press: Berlin, Germany, 2013.

60. Wang, J.; Jiang, Z.; Zhang, L.; Kang, P.; Xie, Y.; Lv, Y.; Xu, R.; Zhang, X. Sonocatalytic degradation of some dyestuffs and comparison of catalytic activities of nano-sized $\mathrm{TiO}_{2}$, nano-sized $\mathrm{ZnO}$ and composite $\mathrm{TiO}_{2} / \mathrm{ZnO}$ powders under ultrasonic irradiation. Ultrason. Sonochem. 2009, 16, 225-231. [CrossRef] [PubMed]

61. Lin, J.; Zhao, X.; Liu, D.; Yu, Z.; Zhang, Y.; Xu, H. The decoloration and mineralization of azo dye C.I. Acid Red 14 by sonochemical process: Rate improvement via Fenton's reactions. J. Hazard. Mater. 2008, 157, 541-546. [CrossRef] [PubMed]

62. Joseph, J.M.; Destaillats, H.; Hung, H.; Hoffmann, M.R. The sonochemical degradation of azobenzene and related azo dyes: Rate enhancements via fenton's reactions. J. Phys. Chem. A 2000, 104, 301-307. [CrossRef]

63. Nam, S.; Han, S.; Kang, J.; Choi, H. Kinetics and mechanisms of the sonolytic destruction of non-volatile organic compounds: Investigation of the sonochemical reaction zone using several $\mathrm{OH}$ monitoring techniques. Ultrason. Sonochem. 2003, 10, 139-147. [CrossRef]

64. Okitsu, K.; Nanzai, B.; Kawasaki, K.; Takenaka, N.; Bandow, H. Sonochemical decomposition of organic acids in aqueous solution: Understanding of molecular behavior during cavitation by the analysis of a heterogeneous reaction kinetics model. Ultrason. Sonochem. 2009, 16, 155-162. [CrossRef] [PubMed]

65. Serpone, N.; Terzian, R.; Hidaka, H.; Pelizzetti, E. Ultrasonic induced dehalogenation and oxidation of 2-, 3-, and 4-chlorophenol in air-equilibrated aqueous media. Similarities with irradiated semiconductor particulates. J. Phys. Chem. 1994, 98, 2634-2640. [CrossRef]

66. Tani, T.; Mädler, L.; Pratsinis, S. Homogeneous ZnO nanoparticles by flame spray pyrolysis. J. Nanopart. Res. 2002, 4, 337-343. [CrossRef] 
67. Mishra, Y.K.; Modi, G.; Cretu, V.; Postica, V.; Lupan, O.; Reimer, T.; Paulowicz, I.; Hrkac, V.; Benecke, W.; Kienle, L.; et al. Direct growth of freestanding $\mathrm{ZnO}$ tetrapod networks for multifunctional applications in photocatalysis, UV photodetection, and gas sensing. ACS Appl. Mater. Interfaces 2015, 7, 14303-14316. [CrossRef] [PubMed]

68. Liqiang, J.; Yichun, Q.; Baiqi, W.; Shudan, L.; Baojiang, J.; Libin, Y.; Wei, F.; Honggang, F.; Jiazhong, S. Review of photoluminescence performance of nano-sized semiconductor materials and its relationships with photocatalytic activity. Sol. Energy Mater. Sol. Cells 2006, 90, 1773-1787. [CrossRef]

69. Augugliaro, V.; Bellardita, M.; Loddo, V.; Palmisano, G.; Palmisano, L.; Yurdakal, S. Overview on oxidation mechanisms of organic compounds by $\mathrm{TiO}_{2}$ in heterogeneous photocatalysis. J. Photochem. Photobiol. C 2012, 13, 224-245. [CrossRef]

(C) 2018 by the authors. Licensee MDPI, Basel, Switzerland. This article is an open access article distributed under the terms and conditions of the Creative Commons Attribution (CC BY) license (http:/ / creativecommons.org/licenses/by/4.0/). 